\title{
Insights into the curing kinetics of epoxy/PLA: Implications of the networking structure
}

\author{
I. D. S. Silva', J. J. P. Barros ${ }^{1}$, A. Albuquerque ${ }^{1}$, N. G. Jaques ${ }^{1}$, M. V. L. Fook ${ }^{1}$, R. M. R. Wellen ${ }^{12 *}$ \\ ${ }^{1}$ Academic Unit of Materials Engineering, Federal University of Campina Grande, 58249-140 Campina Grande, Brazil \\ ${ }^{2}$ Materials Engineering Department, Federal University of Paraiba, 58051-900 João Pessoa, Brazil
}

Received 11 April 2020; accepted in revised form 1 June 2020

\begin{abstract}
The curing kinetics of thermoset-thermoplastic compounds based on diglycidyl ether of bisphenol A (DGEBA), methyl tetrahydrophthalic anhydride (MTHPA) as the hardener, 2,4,6-tris(dimethylaminomethyl)phenol (DEH 35) as a catalyzer, and poly(lactic acid) (PLA) as workable (i.e., with repairable bonds) phase was investigated using Fourier transform infrared spectroscopy (FTIR) and differential scanning calorimetry (DSC). Hydrogen bonding between PLA carbonyl and epoxy hydroxyl and oxirane groups is the main influent interaction taking place, which acts as changing providers (i.e. hydrogen bonded groups able to move) of curing rate and degree of curing as evaluated from the vibration bands and exothermal released heat. With increasing PLA content, the real crosslink density decreases as also the curing rate is delayed. Partially miscibility between epoxy and PLA is proposed, whereas after reaching epoxy's solubility limit PLA precipitates, hence the microstructure is suggested to be composed by the epoxy network, interacted Epoxy/PLA and precipitated PLA. Reported data offer reliable tools to reach the aimed degree of crosslinking, controlling of epoxy microstructure overcoming the brittle fracture providing a wider window of processing and applications.
\end{abstract}

Keywords: polymer blends and alloys, epoxy, PLA, curing kinetics, workable microstructure

\section{Introduction}

Diglycidyl ether of bisphenol A (DGEBA) is an epoxy resin made from epichlorohydrin with bisphenol A and a basic catalyst, whose properties are handled through chemical structure changes performed during curing. DGEBA is widely used in the industry, mainly in electronics and aerospace goods, due to its characters such as adhesion, low shrinkage, high strength, excellent electrical insulation, and corrosion resistance [1-3]. However, low impact strength and non-workability resulted from the three-dimensional reticulated network, are hinderers in applications where toughness is a required property $[4,5]$. Development of epoxy compounds with better performance can be reached upon the addition of thermoplastics to toughening and flexibilizes their stiff networks, expanding the scientific background and technological interest [1-3].

Thermoplastics addition to epoxies besides increasing toughness does not significantly damage other mechanical properties, such as elastic modulus or tensile strength [6-8]. The thermoplastic phase can behave as a workable phase inside the thermoset matrix, currently, with polymerization and phase morphology controlling, the cracked or micro fractured layers are prone to be repaired by supramolecular network reorganizing, especially secondary interactions such as hydrogen bonding [9-12].

Epoxy (DGEBA) has reactive chemical groups such as epoxy ring and hydroxyls, which are able to chemically interact with thermoplastics, such as PCL [13], polycarbonate (PC) [14], poly(hydroxyalkanoates)

$\overline{{ }^{*} \text { Corresponding author, e-mail: wellen.renate@gmail.com }}$ (C) BME-PT 
(PHA) [15], poly(ether ketone) (PEEK) [16] and poly(lactic acid) (PLA) [17]. Specifically for PLA, esters, carboxyl, and hydroxyl in its macromolecular structure favor chemical and physical interactions with polymers in which carboxylic, hydroxyl, peroxide, isocyanate, and epoxide, are present in the polymeric chains [18].

An interesting achievement was reported by Luo et al. [9] who produced workable epoxy (DGEBA)/ PCL compound with reversible adhesive properties attributed to the hydrogen bonding between PCL carbonyl group and an epoxy hydroxyl group. According to Acebo et al. [17], adding $10 \mathrm{wt} \%$ of the copolymer poly(ethylene imine) (PEI) PLA branched (PEI-PLA), led to epoxy curing rate decrease due to the slow mobility of reactive species. Improvement of $16 \%$ in impact strength was reported for epoxy/ PEI-PLA related to neat epoxy, no phase separation was observed. Under appropriate thermal conditions, the crosslinking density of epoxy/PEI-PLA decreased due to PLA ester bonds cleavage, leading to thermal workability. Hameed et al. [19] reported hydrogen bonding in nanostructured epoxy (DGEBA) with triblock copolymer poly( $\varepsilon$-caprolactone)-block-poly (dimethyl siloxane)-block-poly( $\varepsilon$-caprolactone) (PCL-PDMS-PCL) cured with 4,4'-methylenedianiline (MDA); which are interacting through epoxy hydroxyl and PCL carbonyl.

The chemical reactions developed during epoxy curing in contact with thermoplastics greatly influence the whole compound morphology, significant changes are usually verified such as the crosslinking density, the curing kinetics parameters, as well as the melting and crystallization behaviors (for crystallizable thermoplastic) which lead to property changes [7]. Through thermal and chemical analyses, the curing reactions can be elucidated, and the rational control of their mechanisms allows mimicking proper performance for various applications. The main purpose of this work was elucidating the evolution of conversion of epoxy/PLA compounds, defining the phase transition, which takes place along with it applying Fourier-transform infrared spectroscopy (FTIR). The curing kinetics was followed using differential scanning calorimetry (DSC), kinetics and thermodynamic parameters were evaluated. The collected data, besides supporting the understanding of reactions and chemical interactions which take place during compounding, provide appropriate tools to control the desired degree of curing, and therefore the intended microstructure. This work presents a new approach for evaluating the epoxy curing where FTIR and DSC were simultaneously applied, through mutual protocols where both are corroborated, information about the relative and real degrees of conversion are reported as well as specific parameters of the curing, together present an approach not yet reported in the literature.

\section{Experimental}

\subsection{Materials}

Poly(lactic acid) (PLA) Biopolymer 3251, extrusion grade 2003D, was purchased from NatureWorks Ingeo (Minnesota, USA). Diglycidyl ether of bisphenol A - DGEBA (DER 331) with epoxide equivalent weight of 182-192 g/eq, anhydride methyl tetrahydrophthalic (MTHPA) and 2,4,6tris(dimethylaminomethyl)phenol (DEH 35) were supplied by Olin Corporation (São Paulo, Brazil). The chemical structures of raw material, as well as their reactive groups (red and blue highlighted) and suggested interactions between MTHPA/DEH 35, are displayed in Figure 1.

\subsection{Methods}

\subsubsection{Epoxy/PLA compounds}

As the first step, PLA (at contents of 10, 20, 30, and $90 \mathrm{phr}$ ) was dissolved in the uncured epoxy resin using a magnetic stirring; the mixing carried out at $160^{\circ} \mathrm{C}, 800 \mathrm{rpm}$ for $30 \mathrm{~min}$. Afterward, the temperature naturally decreased to $40^{\circ} \mathrm{C}$.

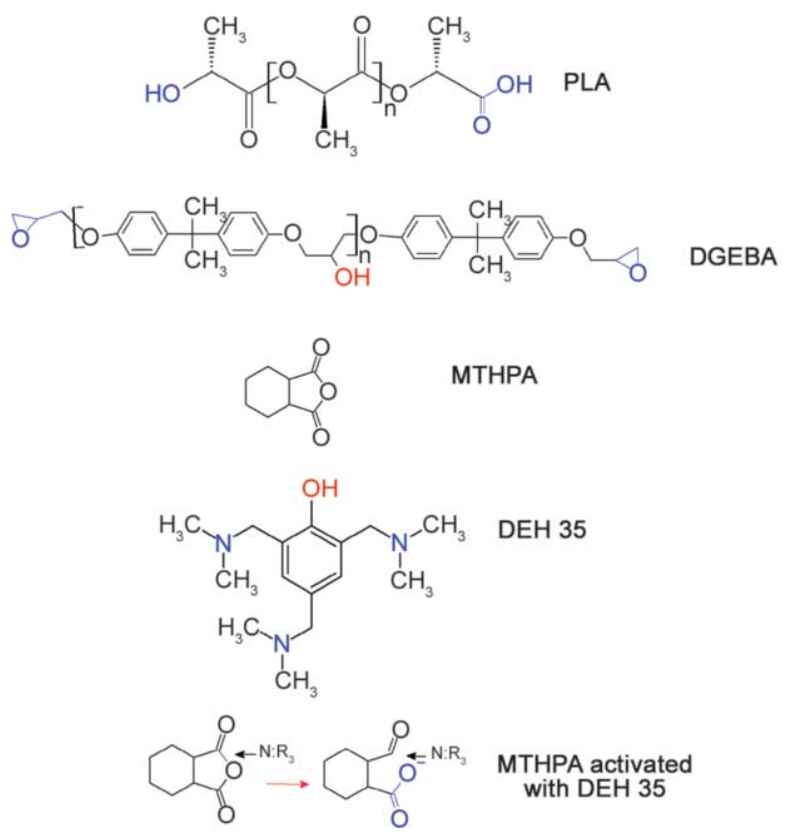

Figure 1. Chemical structures of raw materials. 


\subsubsection{Epoxy/PLA/MTHPA/DEH 35 - uncured compounds}

As the second step, the hardener (MTHPA) and catalyst (DEH 35) were added to the epoxy/PLA. All materials were mixed using a magnetic stirrer for 10 min, at $800 \mathrm{rpm}$, and at $40^{\circ} \mathrm{C}$. Produced compounds and components contents are coded in Table 1.

\subsubsection{Epoxy/PLA/MTHPA/DEH 35 cured compounds under temperature influence}

As the third step, compounds were poured on molds and cured in an oven with the heating rate $10^{\circ} \mathrm{C} / \mathrm{min}$ from ambient temperature $\left(20^{\circ} \mathrm{C}\right)$ to $40,60,80,100$, 120 and $140{ }^{\circ} \mathrm{C}$; compounds were kept at the final temperature for $30 \mathrm{~min}$. This range was based on DSC scans, where at $20^{\circ} \mathrm{C}$ no evidence of curing while at $140 \mathrm{C}$ the curing is complete. Afterward, spectra were collected according to 2.3.1 section. This procedure was performed to gather quantitative information related to the reaction development and interaction among the functional groups, i.e., epoxide ring, hydroxyl, and carboxyl, along with temperature; therefore, to elucidate the curing kinetics using FTIR.

\subsection{Characterization of $E / P / M / D$ compounds}

\subsubsection{Investigation of curing reactions using} FTIR

After the isothermal heating (2.2.3 section) compounds in Table 1 were characterized using FTIR and DSC (as described in 2.3.3. section). Spectra were collected in the wavenumber range 4000 $600 \mathrm{~cm}^{-1}$, with 16 scans and $4 \mathrm{~cm}^{-1}$ resolution, applying ATR mode. The equipment used was Perkin Elmer Spectrum 400 (Waltham, Massachusetts, USA), and data modeling was done in the Spectrum software.

\subsubsection{Investigation of the curing kinetics using FTIR}

The degree of conversion $(\alpha)$ was computed using an adaptation of the Beer-Lambert Law, as shown in Equation (1), in which the reference band used is theoretically constant throughout the reaction $\left(A_{\mathrm{R}}\right)_{0 \rightarrow \mathrm{T}}$, in this case, this is the corresponding band to the elongation vibration of $\mathrm{C}=\mathrm{C}$ bond at $1510 \mathrm{~cm}^{-1}$, characteristic of the aromatic ring; the second band is associated with the reactive functional groups that will take part in the curing reaction $\left(A_{\mathrm{C}}\right)_{0 \rightarrow \mathrm{T}}$, i.e., the band at $910 \mathrm{~cm}^{-1}$ which is associated with the epoxide ring and during the curing development it decreases, due to the epoxy ring opening [20,21].

$\alpha=1-\frac{\left(\frac{A_{\mathrm{C}}}{A_{\mathrm{R}}}\right)_{\mathrm{t}}}{\left(\frac{A_{\mathrm{C}}}{A_{\mathrm{R}}}\right)_{0}}$

\subsubsection{Investigation of the curing kinetics by DSC} The curing of E/P/M/D was monitored using DSC Q20 from TA Instruments (New Castle, DE, USA). Samples with approximately $3 \mathrm{mg}$ were tested in a standard closed aluminum pan under a nitrogen gas flow of $50 \mathrm{ml} / \mathrm{min}$. The samples were thermally heated from 25 to $200^{\circ} \mathrm{C}$, at heating/cooling/reheating rates of $2.5,5,10,15$, and $20^{\circ} \mathrm{C} / \mathrm{min}$.

\section{Results and discussion \\ 3.1. Chemical analysis through FTIR \\ E/P compounds}

FTIR spectra of PLA, epoxy, and E/P are presented in Figure 2. PLA spectra displayed bands at 2995$2946 \mathrm{~cm}^{-1}$ due to the stretching vibrations of $\mathrm{CH}$ $\left(\mathrm{CH}_{2}, \mathrm{CH}_{3}\right)$, at $1748 \mathrm{~cm}^{-1}$ due to $\mathrm{C}=\mathrm{O}$ stretching

Table 1. Codes and contents of produced epoxy/PLA/MTHPA/DEH 35 compounds.

\begin{tabular}{|l|c|c|c|c|}
\hline \multicolumn{1}{|c|}{ Compound } & Epoxy resin & Hardener & Catalyst & Thermoplastic \\
\hline E & DER 331 & MTHPA & DEH 35 & PLA \\
\hline E/M/D & 100 & 87 & 5 & 0 \\
\hline E/P10/M/D & 100 & 87 & 5 & 10 \\
\hline E/P20/M/D & 100 & 87 & 5 & 20 \\
\hline E/P30/M/D & 100 & 87 & 5 & 30 \\
\hline E/P90/M/D & 100 & 87 & 5 & 100 \\
\hline P100 & 100 & 0 & 0 & \\
\hline
\end{tabular}

E - Epoxy resin DGEBA; P - PLA; M - MTHPA; D - DEH 35. 


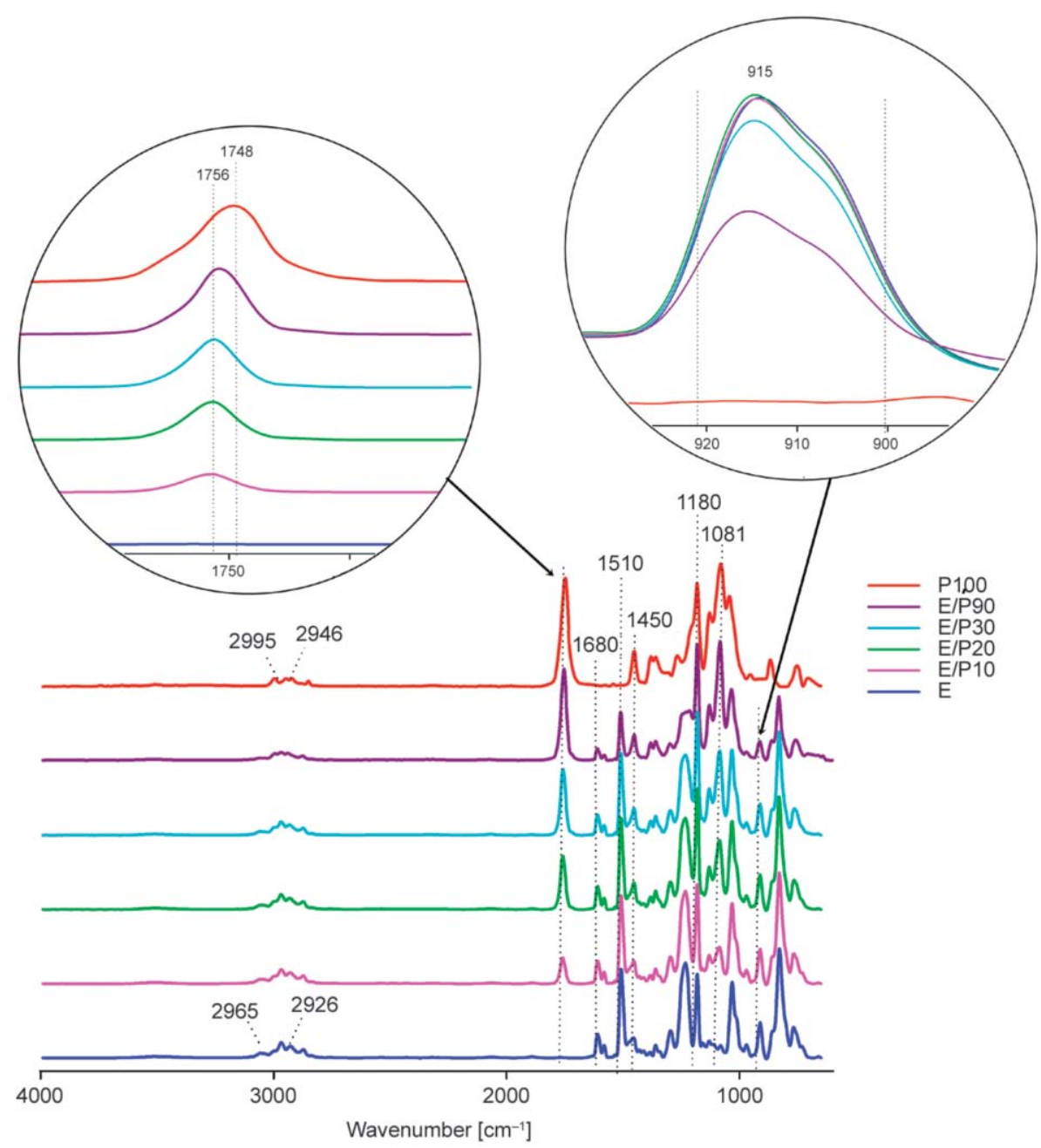

Figure 2. FTIR spectra of PLA, epoxy and E/P (without addition of M/D).

(ester carbonyl), at $1450 \mathrm{~cm}^{-1}$ related to $\mathrm{C}-\mathrm{H}$ bending (scissoring, $\mathrm{CH}_{2}, \mathrm{CH}_{3}$ ), and at $1180-955 \mathrm{~cm}^{-1}$ associated to $\mathrm{C}-\mathrm{O}, \mathrm{C}-\mathrm{O}-\mathrm{C}$ stretching and $\mathrm{OH}$ deformation. Epoxy spectra presented bands at 2965$2873 \mathrm{~cm}^{-1}$ attributed to stretching vibrations of $\mathrm{CH}$ $\left(\mathrm{CH}_{2}, \mathrm{CH}_{3}\right)$, at $1608 \mathrm{~cm}-1$ due to $\mathrm{C}=\mathrm{C}$ stretching on the aromatic ring, at $1510 \mathrm{~cm}^{-1}$ related to $\mathrm{C}=\mathrm{C}$ elongation of the aromatic ring, at $1132 \mathrm{~cm}^{-1}$ attributed to $\mathrm{C}-\mathrm{O}-\mathrm{C}$ elongation, and at $915 \mathrm{~cm}^{-1}$ corresponding to the oxirane $\mathrm{C}-\mathrm{O}$ elongation [22-25].

$\mathrm{E} / \mathrm{P}$ compounds presented displacement of $8 \mathrm{~cm}^{-1}$ related to the carbonyl band of PLA ester group (from
1748 to $1756 \mathrm{~cm}^{-1}$ ), as evidenced in Figure 2 and Table 2, which can be linked to hydrogen bonding between PLA carbonyl and epoxy hydroxyl and/or oxirane group, such secondary bonds can help compound workability, as these are low energy bonds which may repeatedly de-bonding and re-bonding under external agent influence such as heating and/or stressing, without considerable damaging the microstructure. During heating in the temperature range from PLA $T_{\mathrm{g}}$ to near $T_{\mathrm{m}}$, rotational and translational movements of PLA are freely unimpeded, and structural dilation may occur, for subtle flaws such as

Table 2. Main observed bands in FTIR spectra. Compounds and vibration range indicated.

\begin{tabular}{|l|c|c|c|c|c|}
\hline \multicolumn{1}{|c|}{ Compound } & $\begin{array}{c}\text { Oxirane } \\
\mathbf{C}-\mathbf{O}\end{array}$ & $\begin{array}{c}\text { Aromatic ring } \\
\mathbf{C}=\mathbf{C}\end{array}$ & $\begin{array}{c}\text { Ester } \\
\mathbf{C}=\mathbf{O}\end{array}$ & $\begin{array}{c}\text { Carboxyl } \\
\mathbf{C}=\mathbf{O}\end{array}$ & $\begin{array}{c}\text { Anhydride } \\
\mathbf{C}=\mathbf{O}\end{array}$ \\
\hline $\mathrm{P} 100$ & - & - & 1748 & - & - \\
\hline $\mathrm{E}$ & 915 & 1510 & - & - & - \\
\hline $\mathrm{M}$ & - & - & - & - & 1780 \\
\hline $\mathrm{E} / \mathrm{P}$ & 915 & 1510 & 1756 & - & - \\
\hline Uncured E/P/M/D & 915 & 1510 & 1730 & - & 1780 \\
\hline Cured E/P/M/D & - & 1510 & 1730 & 1700 & - \\
\hline
\end{tabular}




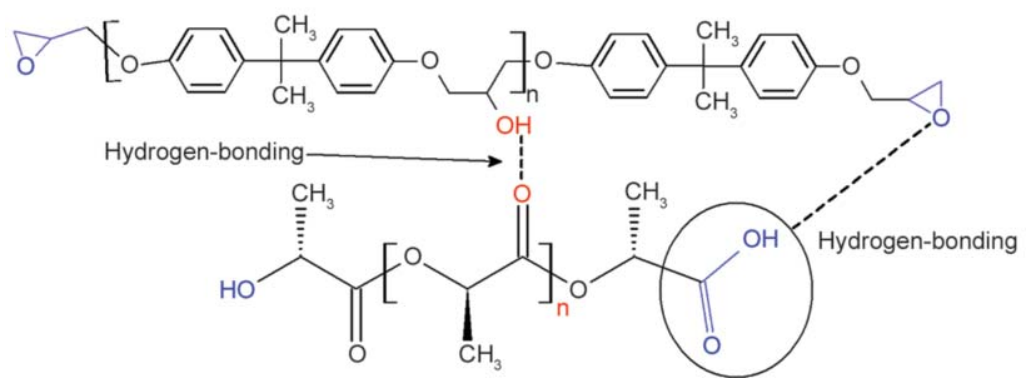

Figure 3. Hydrogen bonding between epoxy and PLA.

micro-cracks living in this environment the propagation can be avoided as well as micro-structural repair can be achieved since PLA in the rubbery or fluid state can fill the micro hollows, reinforcing compound workability, as later on presented in Figure 10. Suggested interactions between epoxy and PLA are presented in Figure 3.

A similar phenomenon was observed by Al-Mulla et al. [26], who suggested hydrogen bonding between the epoxidized palm oil (EPO) oxirane group and PLA terminal hydroxyl. $\mathrm{Xu}$ and $\mathrm{Qu}$ [27] suggested hydrogen bonding between PLA ester and EPO oxirane group. Hydrogen bonding interactions have also been observed between PCL carbonyl and the epoxy hydroxyl, as reported by $\mathrm{Ni}$ and Zheng [28].

Epoxy rings are highly susceptible to react due to the polarity and tension of oxirane. Chemical reactions between epoxide ring and reactive groups, such as hydroxyl and carboxyl from polyesters [29, 30], anhydrides and amines [31], take place with epoxide ring-opening heading to decrease or absence of $915 \mathrm{~cm}^{-1}$ (corresponding to the $\mathrm{CO}$ elongation of epoxy ring) in FTIR spectrum [32], while the band $1510 \mathrm{~cm}^{-1}$, related to $\mathrm{C}=\mathrm{C}$ elongation in aromatic epoxy ring remains unchanged due to thermal and chemical stability of the aromatic group; therefore they can properly be used as reference band during the degree of curing conversion measurements.

In the present work, as illustrated in Figure 2 and Table 3, the band area at $915 \mathrm{~cm}^{-1}$ related to epoxide ring, decreased by 11 and $8 \%$ after adding 30 and $90 \mathrm{phr}$ PLA, respectively, compared to neat epoxy. Nevertheless, the band area at $1510 \mathrm{~cm}^{-1}$ also decreased, establishing a constant ratio between 915 and $1510 \mathrm{~cm}^{-1}$ bands (see Table 3). Although secondary interactions took place between epoxy/PLA $(\mathrm{E} / \mathrm{P})$, it is suggested there were no primary reactions of epoxy ring-opening with PLA hydroxyl and carboxyl. These organic compounds are supposed to be chemically stable under applied mixing parameters.
Table 3. Wavenumber, bands area and ratio (between 915 and $1510 \mathrm{~cm}^{-1}$ ).

\begin{tabular}{|c|c|c|c|}
\hline Compound & $\begin{array}{c}\text { Wavenumber } \\
{\left[\mathrm{cm}^{-1}\right]}\end{array}$ & $\begin{array}{c}\text { Band area } \\
{\left[\mathrm{cm}^{2}\right]}\end{array}$ & $\begin{array}{c}\text { Bands ratio } \\
(1510 / 915)\end{array}$ \\
\hline \multirow{2}{*}{ E } & 915 & 12.340 & \multirow{2}{*}{0.495} \\
\hline & 1510 & 6.100 & \\
\hline \multirow{2}{*}{$\mathrm{E} / \mathrm{P} 10$} & 915 & 12.000 & \multirow{2}{*}{0.500} \\
\hline & 1510 & 6.190 & \\
\hline \multirow{2}{*}{ E/P20 } & 915 & 12.000 & \multirow{2}{*}{0.506} \\
\hline & 1510 & 6.081 & \\
\hline \multirow{2}{*}{ E/P30 } & 915 & 10.930 & \multirow{2}{*}{0.510} \\
\hline & 1510 & 5.588 & \\
\hline \multirow{2}{*}{ E/P90 } & 915 & 5.790 & \multirow{2}{*}{0.508} \\
\hline & 1510 & 2.948 & \\
\hline
\end{tabular}

In E/P without adding MTHPA and DEH 35, only secondary reactions are assumed to take place through hydrogen bonding between PLA carbonyl and epoxy hydroxyl or epoxide ring. Through reaction control, i.e., component contents, temperature, and curing time, the rational control of hydrogen bonds may be reached.

\section{Uncured epoxy/PLA/MTHPA/DEH 35 (E/P/M/D)}

FTIR spectra of uncured $\mathrm{E} / \mathrm{P}$ with the addition of $\mathrm{M} / \mathrm{D}$ are displayed in Figure 4 (from 1000 to $2000 \mathrm{~cm}^{-1}$ ). The carbonyl band was observed between 1730 and $1860 \mathrm{~cm}^{-1}$. In the MTHPA spectrum (not showed) two main carbonyl bands are observed at 1860 and $1780 \mathrm{~cm}^{-1}$, attributed to symmetric and asymmetric vibrations of cyclic anhydride stretching, respectively. The addition of M/D to $\mathrm{E} / \mathrm{P}$, shifted the carbonyl band (PLA ester) from 1756 to $1780 \mathrm{~cm}^{-1}$ (Table 2 and Figure 4). It is also notable a shoulder $\sim 1730 \mathrm{~cm}^{-1}$, which is assumed belonging to PLA $(\mathrm{C}=\mathrm{O})$ ester, it would be reasonable suggesting:

There is a carboxyl group at a lower spectrum range, with distinct binding energy and reactivity to that seen in PLA and MTHPA; therefore, it is hypothesized might be associated with lower energy ester 


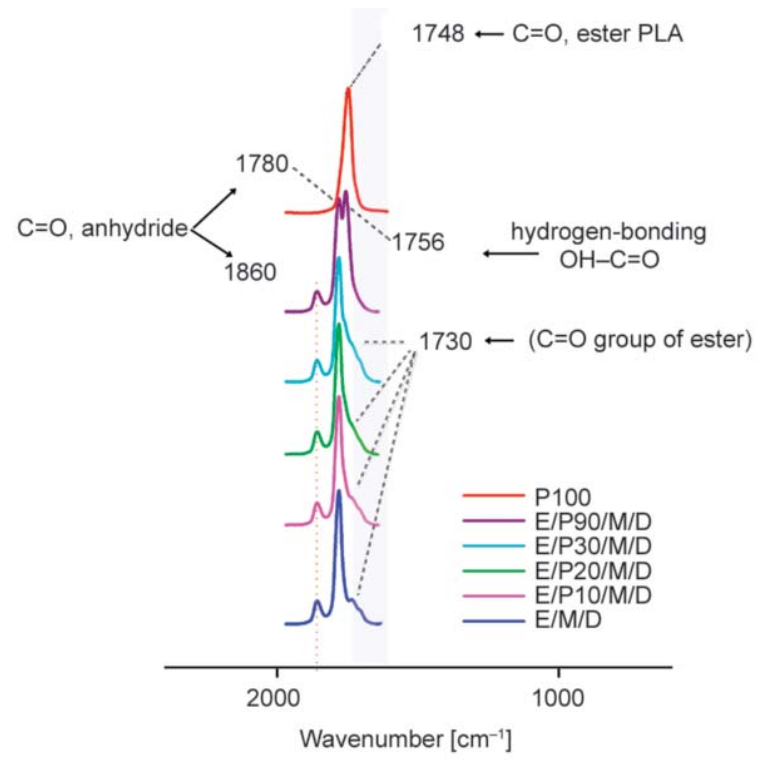

Figure 4. FTIR spectra of uncured E/M/D and E/P/M/D.

bonds as well as secondarily interacting among anhydride, PLA carbonyl, and epoxy hydroxyl.

FTIR spectra of uncured E/P/M/D compounds are shown in Figure 5 for wavenumber between 600 and $4000 \mathrm{~cm}^{-1}$. Among presented spectra only E/P90/M/D showed double band in the carbonyl vibration range, i.e. at $1780 \mathrm{~cm}^{-1}$, assigned to $\mathrm{C}=\mathrm{O}$ from MTHPA, and at $1756 \mathrm{~cm}^{-1}$ assigned to $\mathrm{C}=\mathrm{O}$ from PLA ester, respectively, from this double band phase separation is suggested, i.e., after reaching PLA solubility limit in the epoxy network, PLA precipitates, and a heterogeneous morphology is developed, further on in Figure 9 and Figure 10 additional comments about phase separation mechanism are mentioned. Additionally, verified bands at 1860 and $1780 \mathrm{~cm}^{-1}$ from cyclic anhydride, and at $915 \mathrm{~cm}^{-1}$ from epoxide ring $\mathrm{CO}$, indicate applied mixing process (described in

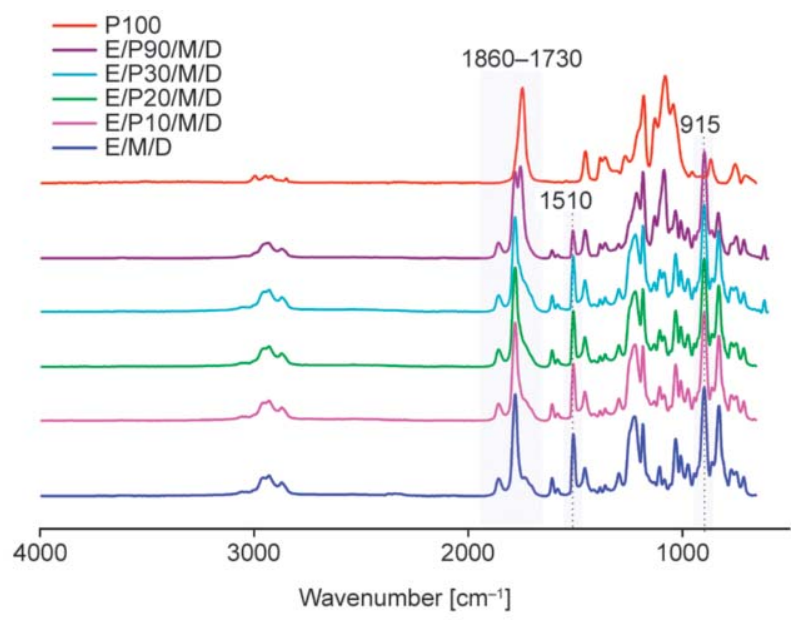

Figure 5. FTIR spectra of uncured E/P/M/D compounds. section 2.2.2), did not promote curing reactions, as desired. The curing developed under the applied procedure of sections 2.2.3 and 2.3.3; afterward, curing kinetics was investigated through FTIR and DSC.

\section{Cured E/P/M/D compounds}

To investigate the curing evolution of $\mathrm{E} / \mathrm{P} / \mathrm{M} / \mathrm{D}$ compounds, selected samples were heated at distinct temperatures ranging from $20^{\circ} \mathrm{C}$ (uncured compounds) to $140{ }^{\circ} \mathrm{C}$ (cured compounds). The evolution of reactive ester, carboxylic acid and anhydride groups during curing reactions followed by FTIR is displayed in Figure 6. Crosslinking reactions taking place during curing are in Figure 7.

From 20 to $100{ }^{\circ} \mathrm{C}$, all compounds presented related vibrations to MTHPA anhydride carbonyl bands at 1860 and $1780 \mathrm{~cm}^{-1}$. Under curing reactions, epoxy hydroxyl reacts by anhydride ring opening to produce semi-esters $\left(\mathrm{C}=\mathrm{O}, 1731 \mathrm{~cm}^{-1}\right)$ and carboxyl acid $\left(\mathrm{C}=\mathrm{O}, 1701 \mathrm{~cm}^{-1}\right)$. After $100^{\circ} \mathrm{C}$ MTHPA bands at 1860 and $1780 \mathrm{~cm}^{-1}$ disappear, suggesting all anhydride groups reacted. The resulting carboxylic acids react with epoxide rings through opening epoxide ring, producing esters $\left(\mathrm{C}=\mathrm{O}\right.$ at $\left.1728 \mathrm{~cm}^{-1}\right)$, and releasing $\mathrm{OH}$ group, thus progressing the curing. At the final curing temperatures, $140^{\circ} \mathrm{C}$, there is only the band at $1728 \mathrm{~cm}^{-1}$ due to ester groups from crosslinking reactions. Similar mechanism was observed for all compounds, with the exception of E/P90/ $\mathrm{M} / \mathrm{D}$, since at $140^{\circ} \mathrm{C}$ the band at $1701 \mathrm{~cm}^{-1}$ due to unreacted carboxyl is still observed.

From the literature database, the curing is usually investigated through epoxy ring-opening $[25,33]$. The bands at 915 and $1510 \mathrm{~cm}^{-1}$, related to epoxide ring and epoxy aromatic ring, respectively, are used as curing progressing indicators.

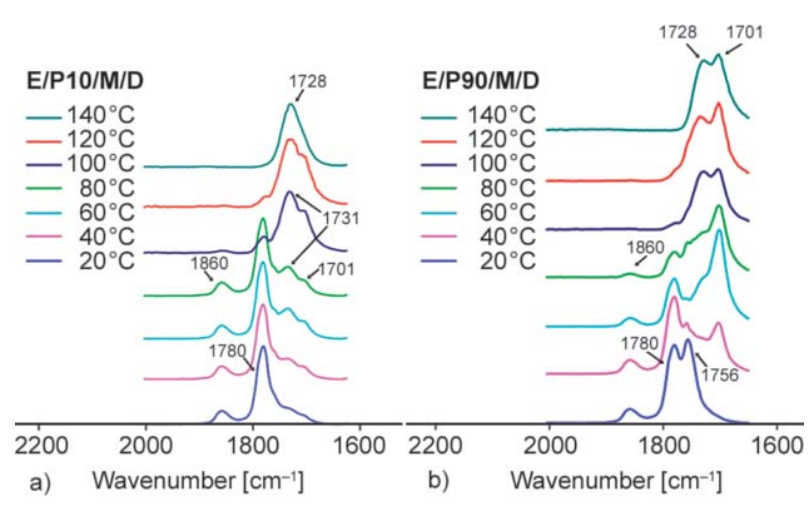

Figure 6. FTIR spectra of E/P/M/D compounds acquired at indicated temperatures. (a) E/P10/M/D and (b) $\mathrm{E} / \mathrm{P} 90 / \mathrm{M} / \mathrm{D}$. 


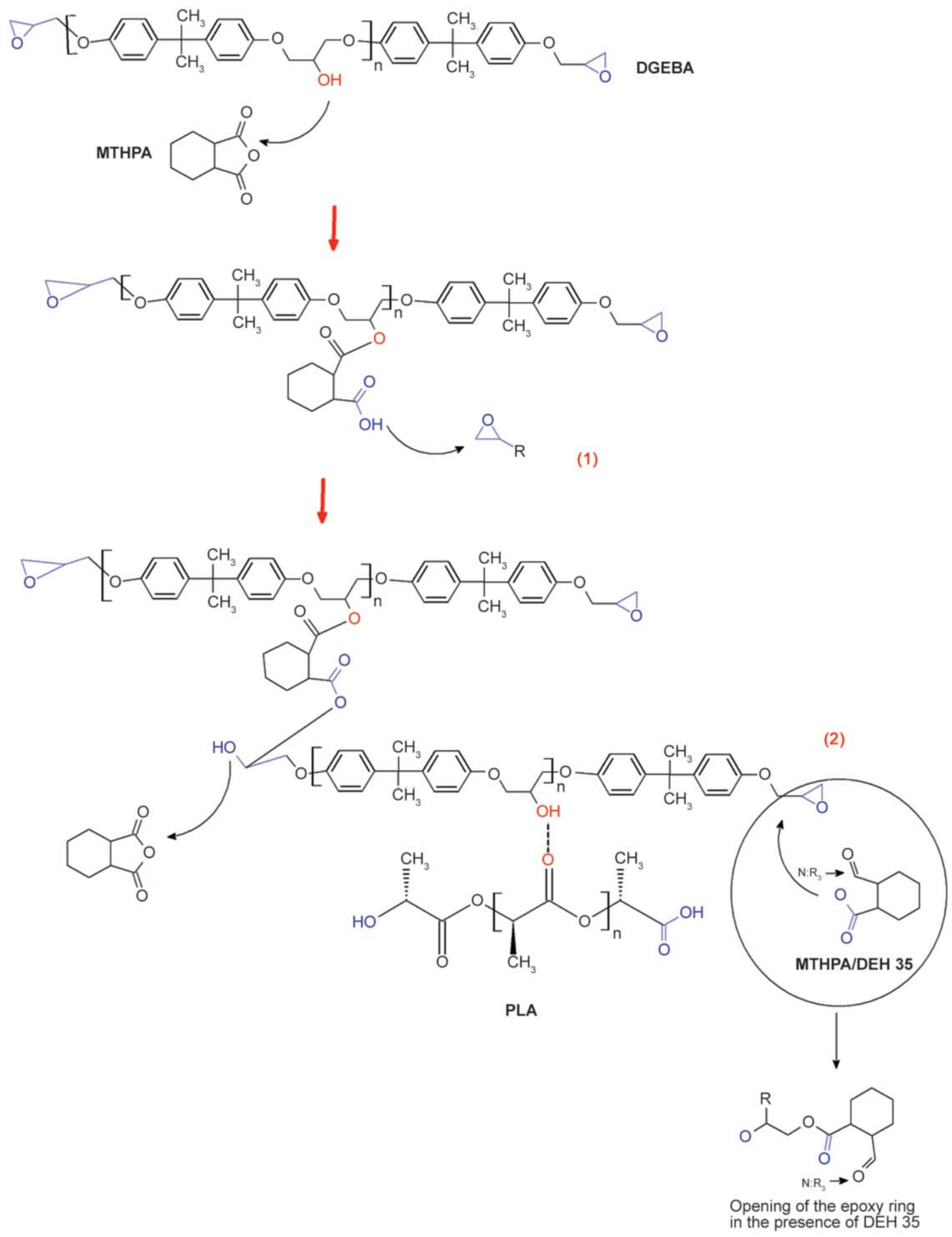

Figure 7. Crosslinking reactions: through esterification of MTHPA and epoxy for E/P/M/D compounds.

As illustrated in Figure 7 during curing:

(1) Epoxy rings are opened by carboxylic acids produced from anhydride with epoxy $\mathrm{OH}$ reactions;

(2) In the presence of tertiary amine (DEH 35) as a catalyst the reaction is improved and additionally takes place through epoxy ring-opening with activated anhydride by amine [34].

FTIR spectral changes, as well as 915 and $1510 \mathrm{~cm}^{-1}$ bands evolution during curing at different temperatures, are shown in Figure 8. Temperature increasing improved crosslinking reactions, conducting to increased band at $3500 \mathrm{~cm}^{-1}(\mathrm{OH}$ stretch) and reduced band at $915 \mathrm{~cm}^{-1}$ due to epoxy ring-opening; absent band at 1860 and $1780 \mathrm{~cm}^{-1}$ due to MTHPA consumption through ring-opening reaction. At all investigated temperatures, the band at $1510 \mathrm{~cm}^{-1}$ remained invariable, evidencing the aromatic ring stability during applied curing parameters.

In investigations based on thermosetting/thermoplastic compounds, through FTIR analyses, Yin and 


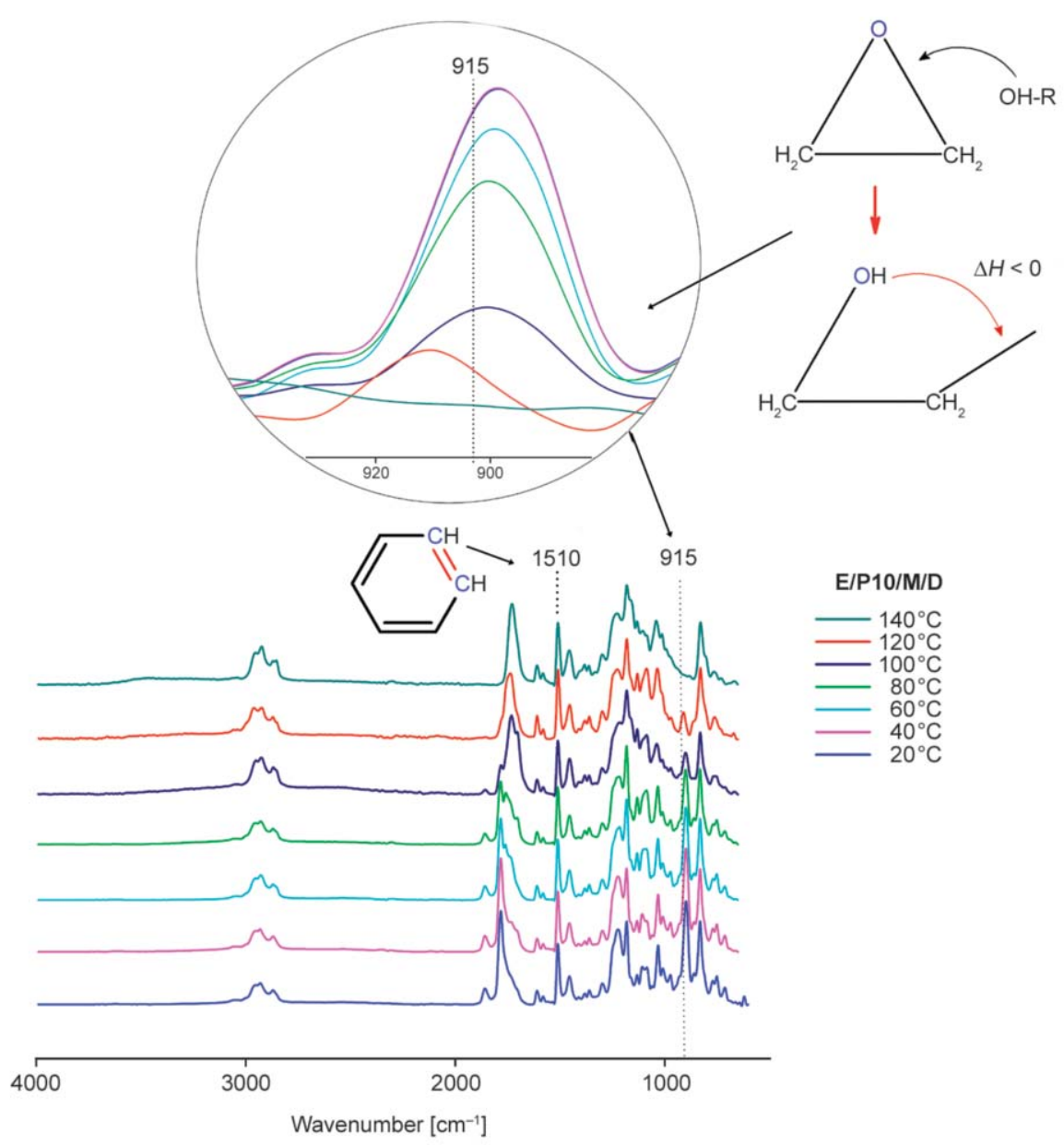

Figure 8. FTIR spectra of E/P/M/D compounds as a function of temperature for E/P30/M/D.

Zheng [35] reported hydrogen bonding interactions among crosslinked DGEBA, PCL and poly (ethylene oxide) (PEO). Hydrogen bonding between epoxy hydroxyl and PEO oxygen atoms was stronger than those between epoxy hydroxyl and PCL carbonyl providing competitive interactions in ternary epoxy compounds. Displaced epoxy hydroxyl band to higher wavenumber was verified by Zheng et al. [36] during epoxy (DGEBA)/PCL curing; additionally, hydrogen bonding was observed between PCL carbonyl and epoxy hydroxyl cured with aromatic amine; related band to PCL carbonyl presented shoulders at lower wavenumber $\left(1702 \mathrm{~cm}^{-1}\right)$ in all epoxy/PCL compounds, such result was attributed to the carbonyl stretching vibration hydrogen bonded.

\section{Curing kinetics measurements by FTIR}

Adopting the reference band at $1510 \mathrm{~cm}^{-1}$ and the curing band at $915 \mathrm{~cm}^{-1}$, the relative degree of curing could be evaluated using Beer-Lambert Law, as plotted in Figure 9.
E/P/M/D compounds presented a sigmoidal 'S' shape indicating curing without discontinuities. In general 'S' plots can be divided into three steps:

$1^{\circ}$ : Reactive centers development (induction period) and reticulation starting, which takes place at slow curing rate, with a degree of conversion $0<\alpha<5 \%$;

$2^{\circ}$ : Reticulation takes place at accelerating rate, the main epoxy network is properly produced in this stage, with a degree of conversion $5<\alpha<90 \%$;

$3^{\circ}$ : The reticulated system hinders the molecular groups from moving freely, decelerating the curing rate; at this stage, the reaction is governed by a diffusional mechanism, with a degree of conversion $>90 \%$.

Nevertheless, from Figure 9, a distinct rate profile is clearly verified for $\mathrm{E} / \mathrm{P} 90 / \mathrm{M} / \mathrm{D}$; for the $2^{\circ}$ stage its curing rate is higher than the others. Two assumptions should be pointed here:

$1^{\circ}$ : ' $\mathrm{S}$ ' plots are built from the rational integration of FTIR bands, i.e., at the band beginning is 


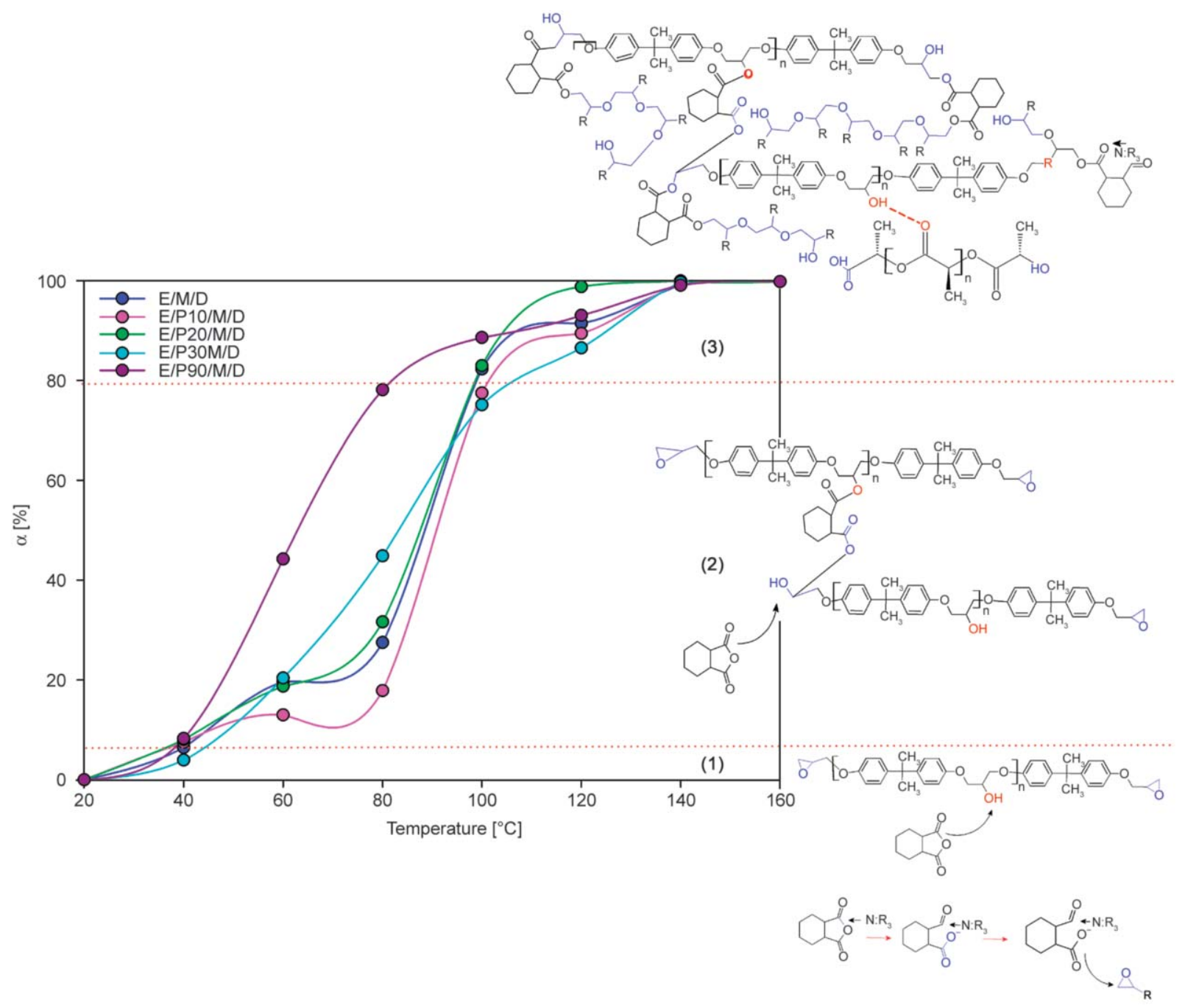

Figure 9. Degree of conversion estimated using Beer-Lambert Law.

assumed $\alpha=0$ and at the end $\alpha=100 \%$, therefore based on this range, the relative degree of conversion is reported (which it always goes from 0 to $100 \%$ ).

$2^{\circ}$ : According to DSC released enthalpy as presented in Table 4, increasing PLA content $\Delta H$ decreased, i.e., lower real degree of epoxy reticulation. Although ' $S$ ' plot presents a higher degree of conversion, it is worth mentioning based on the curing $\Delta H$ (as reported from DSC scans and presented in Table 4) lower crosslinked epoxy content is present, i.e., fewer hinderers to the molecular movements; additionally, epoxy oligomers (and monomers) are present which improve increased PLA solubility into the epoxy network.

Related to epoxy compounds with 10 and $20 \mathrm{phr}$ PLA, their sigmoids presented similar aspects to the neat epoxy one, whereas at $30 \mathrm{phr}$ PLA the sigmoid aspect is between neat epoxy and E/P90/M/D. Phase separation mechanisms such as spinodal decomposition and nucleation and growth are suggested taking place along with the curing progressing. In general, for $\mathrm{E} / \mathrm{P} / \mathrm{M} / \mathrm{D}$ compounds, the reaction-induced phase separation occurs because of the increment in the epoxy molecular weight as the curing reaction proceeds, thereby resulting in PLA precipitation as the second phase.

A schematic microstructure development as temperature function is proposed in Figure 10, from which, based on the above discussion, some suggestions can be hypothesized.

In stage 1, crosslinked epoxy, interacted PLA, precipitated PLA, and micro-cracks are assumed to be present. At temperatures lower to $T_{\mathrm{g}}$ the compound is in the solid/stiff state, being unable to significantly deforming; in this state, the epoxy compound fracture is brittle, i.e., without energy consumption.

In stage 2, at temperatures nearby $T_{\mathrm{g}}$, PLA macromolecular movements take place, hydrogen-bonding 
Table 4. Thermodynamics and kinetics curing parameters E/P/M/D.

\begin{tabular}{|c|c|c|c|c|c|c|}
\hline Compounds & $\begin{array}{c}\boldsymbol{\Phi} \\
{\left[{ }^{\circ} \mathbf{C} / \mathbf{m i n}\right]}\end{array}$ & 2.5 & 5 & 10 & 15 & 20 \\
\hline \multirow{5}{*}{ E/M/D } & $C_{\max } \quad\left[\min ^{-1}\right]$ & 0.0995 & 0.1803 & 0.3394 & 0.4971 & 0.7423 \\
\hline & \begin{tabular}{|ll}
$T_{0.01}$ & {$\left[{ }^{\circ} \mathrm{C}\right]$} \\
\end{tabular} & 71.18 & 77.90 & 88.08 & 96.11 & 106.86 \\
\hline & \begin{tabular}{|ll}
$T_{\mathrm{p}}$ & {$\left[{ }^{\circ} \mathrm{C}\right]$} \\
\end{tabular} & 108.01 & 119.90 & 130.54 & 138.94 & 147.80 \\
\hline & $\begin{array}{|ll|}T_{0.99} & {\left[{ }^{\circ} \mathrm{C}\right]} \\
\end{array}$ & 149.72 & 153.89 & 165.38 & 169.82 & 177.11 \\
\hline & $\Delta H \quad[\mathrm{~J} / \mathrm{g}]$ & 239.4 & 220.8 & 248.92 & 215.13 & 251.39 \\
\hline \multirow{6}{*}{$\mathrm{E} / \mathrm{P} 10 / \mathrm{M} / \mathrm{D}$} & $C_{\max } \quad\left[\min ^{-1}\right]$ & 0.1065 & 0.1923 & 0.3870 & 0.5524 & 0.7022 \\
\hline & \begin{tabular}{|ll}
$T_{0.01}$ & {$\left[{ }^{\circ} \mathrm{C}\right]$} \\
\end{tabular} & 71.60 & 80.06 & 93.03 & 101.82 & 100.30 \\
\hline & $\begin{array}{ll}T_{\mathrm{p}} & {\left[{ }^{\circ} \mathrm{C}\right]} \\
\end{array}$ & 111.60 & 123.39 & 134.69 & 141.73 & 147.23 \\
\hline & \begin{tabular}{|ll}
$T_{0.99}$ & {$\left[{ }^{\circ} \mathrm{C}\right]$} \\
\end{tabular} & 135.24 & 146.18 & 156.50 & 165.45 & 173.26 \\
\hline & $\begin{array}{ll}\Delta H & {[\mathrm{~J} / \mathrm{g}]}\end{array}$ & 259.03 & 195.9 & 231.21 & 234.6 & 249.88 \\
\hline & $\alpha_{\text {real }} \quad[\%]$ & 100.0 & 75.0 & 88.9 & 90.2 & 96.1 \\
\hline \multirow{6}{*}{$\mathrm{E} / \mathrm{P} 20 / \mathrm{M} / \mathrm{D}$} & $C_{\max } \quad\left[\min ^{-1}\right]$ & 0.1331 & 0.1940 & 0.3530 & 0.5111 & 0.6314 \\
\hline & \begin{tabular}{|ll}
$T_{0.01}$ & {$\left[{ }^{\circ} \mathrm{C}\right]$} \\
\end{tabular} & 76.94 & 82.78 & 90.85 & 97.84 & 100.38 \\
\hline & {$\left[{ }^{\circ} \mathrm{C}\right]$} & 109.19 & 121.15 & 132.95 & 139.71 & 144.82 \\
\hline & \begin{tabular}{|ll}
$T_{0.99}$ & {$\left[{ }^{\circ} \mathrm{C}\right]$} \\
\end{tabular} & 123.32 & 141.39 & 157.65 & 167.17 & 174.84 \\
\hline & $\begin{array}{ll}\Delta H & {[\mathrm{~J} / \mathrm{g}]}\end{array}$ & 175.27 & 168.97 & 183.60 & 162.89 & 188.23 \\
\hline & {$[\%]$} & 67.4 & 65.0 & 70.6 & 62.6 & 72.4 \\
\hline \multirow{6}{*}{$\mathrm{E} / \mathrm{P} 30 / \mathrm{M} / \mathrm{D}$} & $C_{\max }\left[\min ^{-1}\right]$ & 0.0829 & 0.1743 & 0.2991 & 0.4705 & 0.6298 \\
\hline & $\begin{array}{ll}T_{0.01} & {\left[{ }^{\circ} \mathrm{C}\right]} \\
\end{array}$ & 66.65 & 75.83 & 82.21 & 89.91 & 98.44 \\
\hline & {$\left[{ }^{\circ} \mathrm{C}\right]$} & 103.33 & 116.41 & 126.16 & 134.91 & 142.78 \\
\hline & \begin{tabular}{|ll}
$T_{0.99}$ & {$\left[{ }^{\circ} \mathrm{C}\right]$} \\
\end{tabular} & 152.44 & 155.24 & 166.69 & 168.19 & 176.00 \\
\hline & $\Delta H \quad[\mathrm{~J} / \mathrm{g}]$ & 167.49 & 204.75 & 162.41 & 196.52 & 214.03 \\
\hline & {$[\%]$} & 64.40 & 78.75 & 62.50 & 75.60 & 82.30 \\
\hline \multirow{6}{*}{ E/P90/M/D } & $C_{\max } \quad\left[\min ^{-1}\right]$ & 0.0865 & 0.1127 & 0.2419 & 0.4401 & 0.5480 \\
\hline & $\begin{array}{ll}T_{0.01} & {\left[{ }^{\circ} \mathrm{C}\right]}\end{array}$ & 70.40 & 82.37 & 91.84 & 102.38 & 109.58 \\
\hline & {$\left[{ }^{\circ} \mathrm{C}\right]$} & 108.50 & 131.06 & 138.85 & 140.96 & 146.21 \\
\hline & \begin{tabular}{|ll}
$T_{0.99}$ & {$\left[{ }^{\circ} \mathrm{C}\right]$} \\
\end{tabular} & 128.24 & 168.90 & 180.07 & 170.63 & 179.29 \\
\hline & $\begin{array}{ll}\Delta H & {[\mathrm{~J} / \mathrm{g}]}\end{array}$ & 101.47 & 72.35 & 111.99 & 98.76 & 110.77 \\
\hline & {$[\%]$} & 39.0 & 27.8 & 43.1 & 38.1 & 42.7 \\
\hline
\end{tabular}

$C_{\max }$ : curing rate at the highest peak intensity. $T_{0.01}$ : temperature at $0.01^{\circ}$ of conversion (assumed as initial curing temperature). $T_{\mathrm{p}}$ : curing peak temperature. $T_{0.99}$ : temperature at $0.99^{\circ}$ of conversion (assumed as final curing temperature). $\Delta H$ : released heat during curing. $\alpha_{\text {real }}$ : real degree of curing, $\alpha_{\text {real }}=\Delta H_{\text {released }} / \Delta H_{\text {full }}$ where: $\Delta H_{\text {released }}$ is the released heat during curing and $\Delta H_{\text {full }}$ is the full heat of epoxy (DGEBA) curing, assumed as $260 \mathrm{~J} / \mathrm{g}$.

interactions between epoxy and PLA can move (rotational and translational movements), bonding and de-bonding interactions are expected to occur between epoxy and PLA depending on temperature and composition. Precipitated PLA is in the rubbery state, which might provide additional deformation as well as hiders the faster micro-cracks propagation.

In stage 3 , at temperatures nearby $160^{\circ} \mathrm{C}$ (usual PLA melting), PLA is in the fluid state, macromolecular movements are intensified, and microcracks nearby fluid PLA might be filled, hindering the brittle fracture.

The curing parameters such as temperature, heating rates, time and reagent content display direct influence on the developed reactions leading to changes in the crosslinking morphology and density; therefore, the curing kinetics of $\mathrm{E} / \mathrm{P}$ was also followed using DSC aiming to elucidate the kinetics and thermodynamic parameters as well as to collect correct data.

\subsection{Curing analysis through DSC}

Figure 11 shows nonisothermal DSC scans of epoxy and $\mathrm{E} / \mathrm{P} / \mathrm{M} / \mathrm{D}$ compounds at applied heating rates. During the first heating, an exothermic peak was observed for all compounds, indicating the curing reaction, which was observed ranging $\Delta T$ from 70 to $180^{\circ} \mathrm{C}$ with the temperature peak $T_{\mathrm{p}}$ ranging from 105 to $150^{\circ} \mathrm{C}$, depending on the heating rate and composition, in general peaks were displaced to higher temperatures upon the increase of the heating rates 


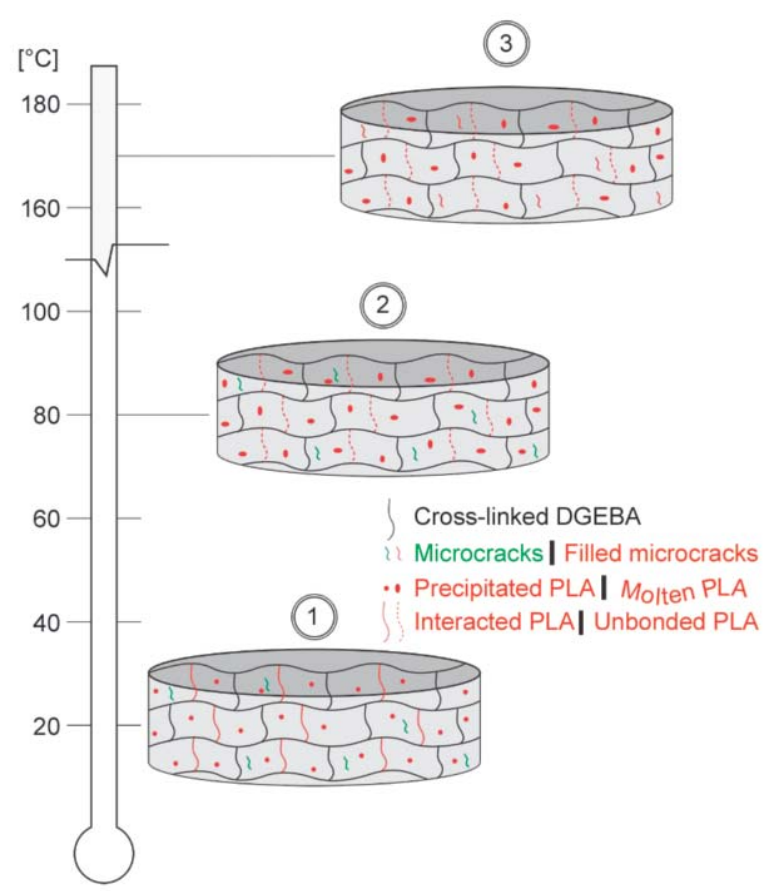

Figure 10. Proposed microstructure development (in cases where micro-cracks are present) for epoxy/PLA as temperature function.
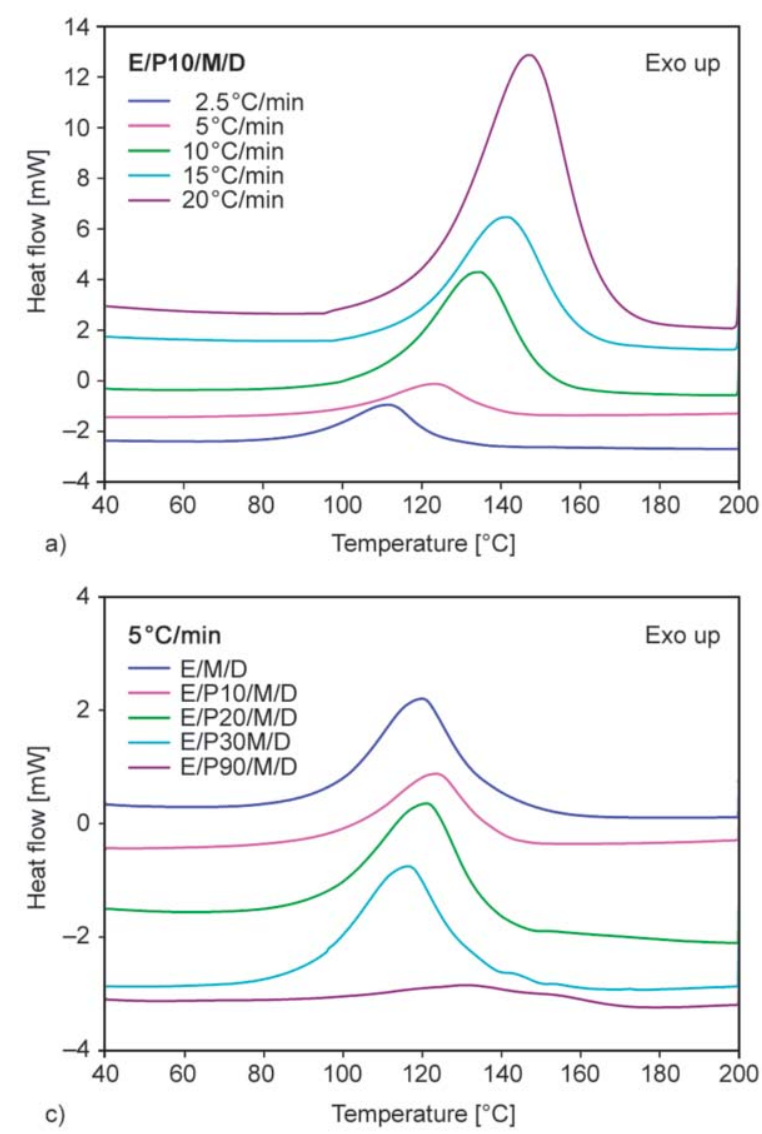

from 2.5 to $20^{\circ} \mathrm{C} / \mathrm{min}$ due to the time lag effect. All DSC scans presented a single bell-shaped peak, which corresponds to the ring-opening reaction of the epoxy oxirane group with $\mathrm{M} / \mathrm{D}$, corroborating the FTIR results [37]. Neither $T_{\mathrm{g}}$ nor PLA melting were detected during the first heating, suggesting PLA phase is dissolved or trapped in the epoxy network, during the reheating stage $T_{\mathrm{g}} \mathrm{S}$ were measured and are presented in Table 5 [38].

Upon 10 and 20 phr of PLA addition, the exothermic peaks were displaced to higher temperatures, which may be related to PLA functional groups that compete and/or hinder the crosslinking reactions, at $90 \mathrm{phr}$ PLA the effect is clearly evidenced, as illustrated in Figure 11c [39]. However, at $30 \mathrm{phr}$ PLA, the opposite behavior is observed, i.e., apparently, the curing is improved. Related to the exothermic enthalpy $\Delta H$, it decreased upon PLA addition leading to decreased crosslinking density; based on FTIR data presented above, it is assumed PLA reacts with the epoxy system, the lower the epoxy network molecular weight,
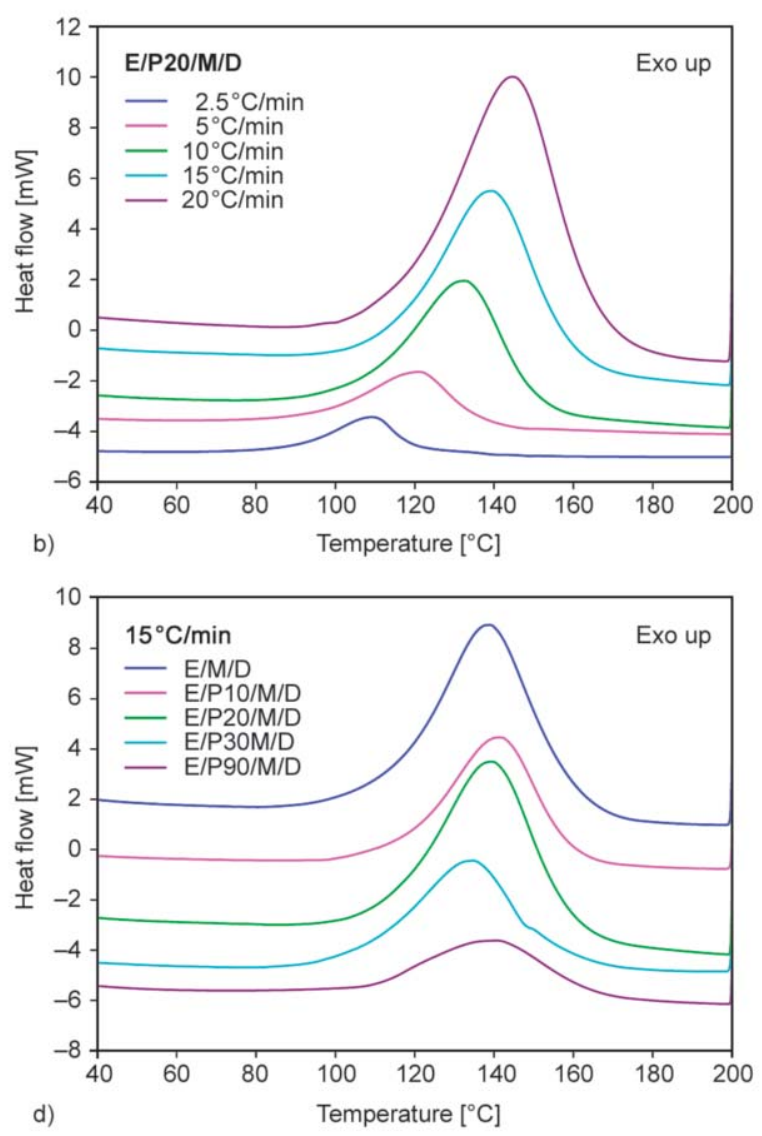

Figure 11. DSC scans of E/P/M/D compounds. a) E/P10/M/D and b) E/P20/M/D, at indicated heating rates. c) and d) $\mathrm{E} / \mathrm{P} / \mathrm{M} / \mathrm{D}$ compounds heated at 5 and $15^{\circ} \mathrm{C} / \mathrm{min}$, respectively. 
Table 5. $T_{\mathrm{g}}$ of E/P/M/D compounds.

\begin{tabular}{|l|c|r|r|r|r|}
\hline \multirow{2}{*}{ Composition } & \multicolumn{5}{|c|}{$\begin{array}{c}\text { Heating rate } \\
{\left[{ }^{\circ} \mathbf{C} \cdot \mathbf{m i n}^{-1} \mathbf{l}\right.}\end{array}$} \\
\cline { 2 - 6 } & $\mathbf{2 . 5}$ & $\mathbf{5}$ & $\mathbf{1 0}$ & $\mathbf{1 5}$ & $\mathbf{2 0}$ \\
\hline $\mathrm{E} / \mathrm{M} / \mathrm{D}$ & 116.50 & 113.62 & 116.65 & 112.14 & 112.14 \\
\hline $\mathrm{E} / \mathrm{P} 10 / \mathrm{M} / \mathrm{D}$ & 104.62 & 102.89 & 107.10 & 109.68 & 108.85 \\
\hline $\mathrm{E} / \mathrm{P} 20 / \mathrm{M} / \mathrm{D}$ & 112.30 & 107.08 & 107.89 & 106.54 & 109.64 \\
\hline $\mathrm{E} / \mathrm{P} 30 / \mathrm{M} / \mathrm{D}$ & 114.38 & 113.88 & 119.62 & 117.50 & 119.64 \\
\hline E/P90/M/D & 71.94 & 55.30 & 53.58 & 40.82 & 37.61 \\
\hline & 128.69 & 99.14 & 90.71 & 78.11 & 76.15 \\
\hline
\end{tabular}

the greater the solubility with PLA. Decreased degree of reticulation and interactions with PLA, are supposed to be properly characters for increasing the workability of $\mathrm{E} / \mathrm{P} / \mathrm{M} / \mathrm{D}$ system.

As observed by previous researchers addition of $20 \mathrm{wt} \%$ hydroxyl-functionalized hyper-branched poly(ester amide) (HBP) provided accelerate effect in the early stages of epoxy (DGEBA)/MTHPA curing, which was attributed to the high hydroxyl content in HBP that favored the non-catalyzed mechanism [40].

Figure 12 and Table 5 illustrate the glass transition temperature $\left(T_{\mathrm{g}}\right)$ of cured $\mathrm{E} / \mathrm{P} / \mathrm{M} / \mathrm{D}$ acquired during the second heating. For compounds with 10, 20 and $30 \mathrm{phr}$ PLA only one $T_{\mathrm{g}}$ was observed around $110^{\circ} \mathrm{C}$ associated with epoxy $T_{\mathrm{g}}$, whereas the compound with $90 \mathrm{phr}$ PLA, two $T_{\mathrm{g}} \mathrm{s}$ were verified, i.e., the PLA and epoxy ones, evidencing the phase separation between epoxy and PLA, most due in compounds with $90 \mathrm{phr}$ PLA a different reaction mechanism takes place, such as esterification, rather than epoxy ring-opening. As shown in Table 5, epoxy $T_{\mathrm{g}}$ decreases upon PLA addition. In general, $T_{\mathrm{g}}$ of epoxy resins tends to increase with the curing development, since crosslinking stiffs the microstructure hindering rotational and translational molecular movements. Nevertheless, due to the PLA addition, these molecular movements took place with lower energy consumption most due to the epoxy lower crosslinked density and precipitated PLA, configuring the workable character of $\mathrm{E} / \mathrm{P} / \mathrm{M} / \mathrm{D}$ compound related to neat epoxy.

In previous researches based on DGEBA/PCL and poly (ether sulfone) (PES)/DGEBA before curing one well defined $T_{\mathrm{g}}$ was verified; nevertheless, upon polymerization, the formulations were no longer miscible. In those cases, after curing the phase separation process was induced, which depended on the curing composition and temperature, higher $T_{\mathrm{g}} \mathrm{s}$ were observed for completely cured systems, while lower $T_{\mathrm{g}} \mathrm{S}$ were seen in partially reticulated ones $[41,42]$. Plots of the relative degree of conversion $(\alpha)$ versus temperature are presented in Figure 13. The sigmoidal shape was observed for all compounds, suggesting the autocatalytic curing kinetics mechanism $[43,44]$. Following the curing, the reaction undergoes gelation (liquid-to-rubber transition) and vitrification (rubber-to-glass transition). In the first stage of curing, $0<\alpha<5 \%$, the reaction rate is slow and gradually increases as the curing advances; in the second stage $5<\alpha<90 \%$ the reaction develops at higher rates due to the high reactive groups' concentration and easy molecular movement, in the third stage $\alpha>90 \%$ the curing rate decelerates because of lower functional groups concentration and increased viscosity (dense network) which reduces the molecular mobility at this point the curing is translated from kinetics to diffusional control [44-46].

The gel point or gelation defined as the critical degree of branching where an infinite network and an insoluble material is formed is supposed to be
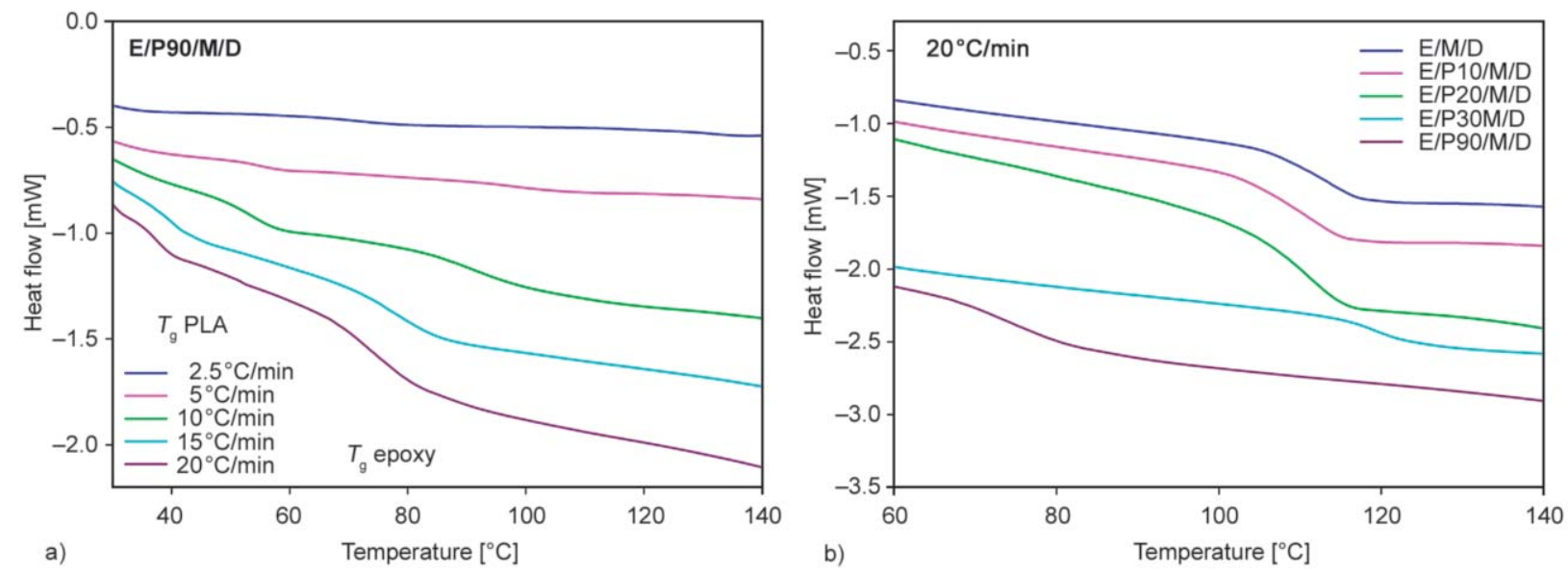

Figure 12. $T_{\mathrm{g}}$ of $\mathrm{E} / \mathrm{P} / \mathrm{M} / \mathrm{D}$ compounds. a) $\mathrm{E} / \mathrm{P} 90 / \mathrm{M} / \mathrm{D}$ at indicated heating rates. b) $\mathrm{E} / \mathrm{P} / \mathrm{M} / \mathrm{D}$ compounds heated at $20^{\circ} \mathrm{C} / \mathrm{min}$. 

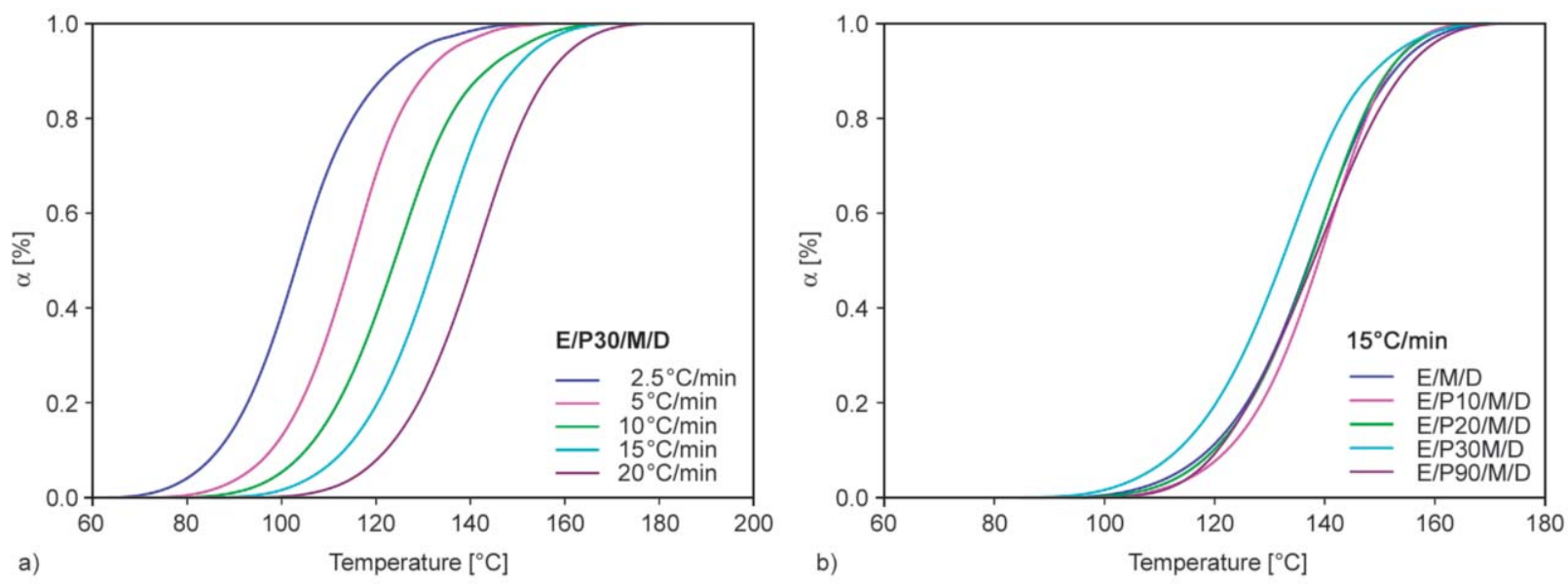

Figure 13. Degree of conversion of $\mathrm{E} / \mathrm{P} / \mathrm{M} / \mathrm{D}$ compounds. a) $\mathrm{E} / \mathrm{P} 30 / \mathrm{M} / \mathrm{D}$ at indicated heating rates. b) E/P/M/D compounds heated at $15^{\circ} \mathrm{C} / \mathrm{min}$.

approximately $\alpha>50 \%$ (i.e., during the second stage), from DSC scans both PLA and higher heating rate act delaying it. After the gelation, successive crosslinking reactions increase the crosslink density, and the stiffness of epoxy is steadily increased, leading, at the end of the process, to the glassy structure (vitrification) of the fully cured thermoset. In this way, PLA providing repairable bonds with epoxy network is considered useful for interlamellar toughening or inter-parts adhesion applications $[45,46]$.

The degree of conversion rate $\left(\mathrm{d}_{\alpha} / \mathrm{d}_{\mathrm{t}}\right)$ as $\alpha$ function is presented in Figure 14. Increasing the heating rates increased $\left(\mathrm{d}_{\alpha} / \mathrm{d}_{\mathrm{t}}\right)$, plots presented a single bell-shape with a maximum ranging from 0.4 to 0.6 [\%], suggesting the reaction mechanism did not change upon PLA addition nor applied heating rates.

Related to E/P30/M/D, from Figure 13b, it cures at lower temperatures which could suggest occurring at faster curing rates; however, from Figure 14 it is just faster than $\mathrm{E} / \mathrm{P} 90 / \mathrm{M} / \mathrm{D}$. Although in the sigmoid in Figure 9 for E/P90/M/D if assumed the degree of

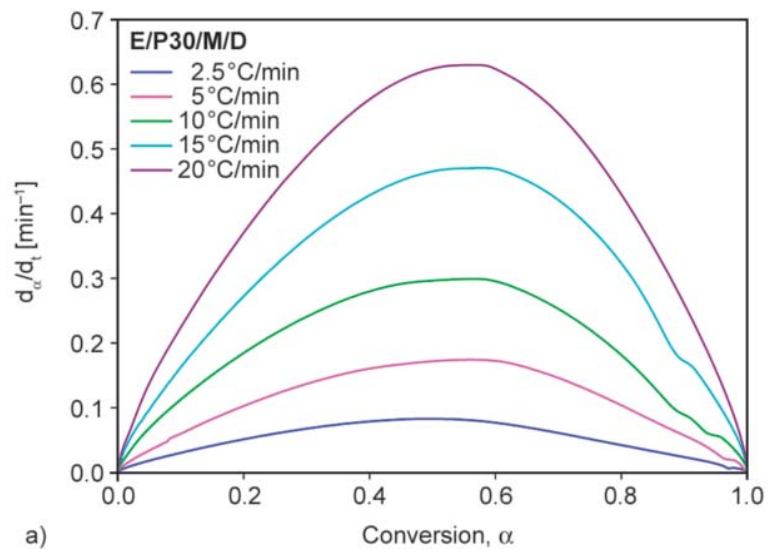

conversion at the same temperature, E/P90/M/D shows higher (relative) conversion but slower curing rate.

Thermodynamics and kinetics parameters computed from DSC scans such as the maximum curing rate $C_{\max }$, released heat during curing $\Delta H$, real degree of curing $\left(\alpha_{\text {real }}\right)$, and curing peak temperatures $\left(T_{0.01}\right.$, $\left.T_{\mathrm{p}}, T_{0.99}\right)$ are presented in Table 4 . Figure 15 graphically displays $C_{\max }, T_{\mathrm{p}}$, and $\Delta H$ as heating rate function, $C_{\max }$ and $T_{\mathrm{p}}$ (as well as $T_{0.01}$ and $T_{0.99}$ ) increased with the heating rates, regarding the PLA addition effect for these parameters, its influence is not clearly defined contrarily to the already verified in Figure 14. Relate to $\Delta H$ while the heating rates have no significant influence, the released heat during curing is strongly dependent on the added PLA content, similarly, the heating rate does not significantly influence $\alpha_{\text {real }}$, contrarily PLA greatly modifies it. Based on these reported data, parameters as temperature, heating rate, and thermoplastic content can be assumed as efficient tools on curing manipulation.

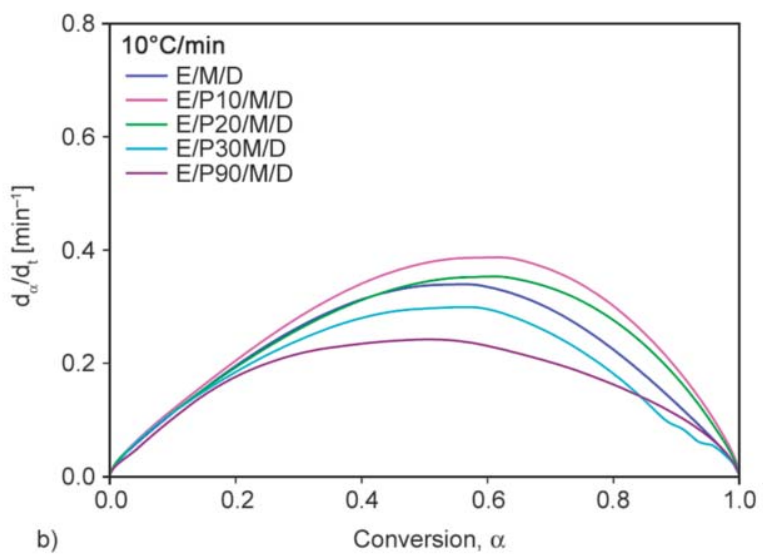

Figure 14. Conversion rate of $\mathrm{E} / \mathrm{P} / \mathrm{M} / \mathrm{D}$ compounds. a) $\mathrm{E} / \mathrm{P} 30 / \mathrm{M} / \mathrm{D}$ at indicated heating rates. b) E/P/M/D compounds heated at $10^{\circ} \mathrm{C} / \mathrm{min}$. 

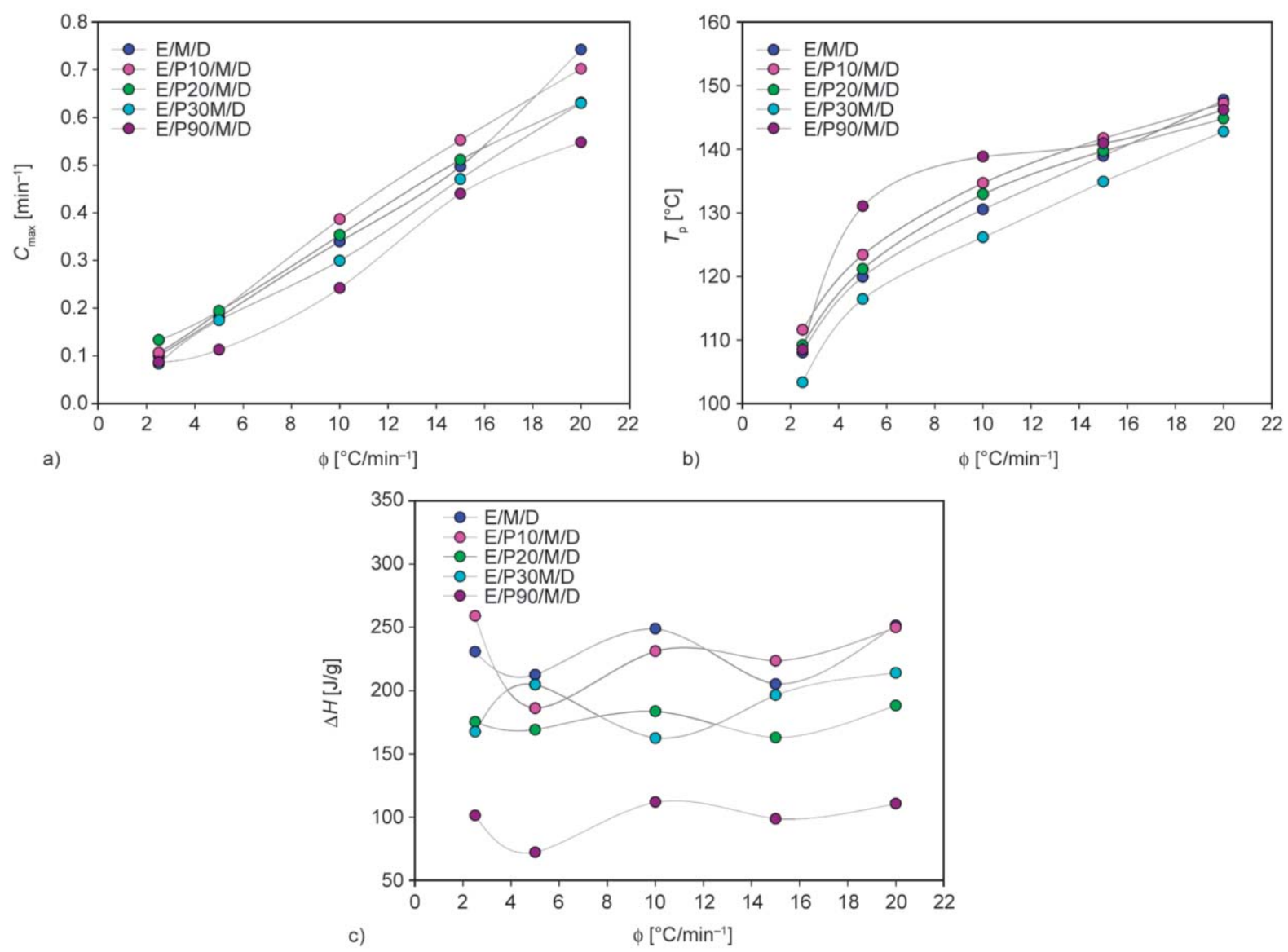

Figure 15. Effect of heating rates and PLA content on the curing parameters of E/P/M/D compounds. a) $C_{\max }$. b) $T_{\mathrm{p}}$. c) $\Delta H$.

\section{Conclusions}

Curing of DGEBA/MTHPA/DEH 35/PLA was followed using FTIR and DSC. From FTIR spectra PLA interacts with the epoxy system mostly by hydrogen bonding, improving PLA solubility in the epoxy matrix. Upon PLA addition, kinetics and thermodynamics parameters of epoxy curing are modified, the proper use of these parameters can lead to high-performance production. PLA might improve toughening in epoxy, which presented lower $T_{\mathrm{g}}$ as well as lower crosslinked network. Workable microstructures are suggested, which are based on lower energy bonds with freer movements related to neat epoxy; they may improve recovering of damaged areas such as micro-cracks repairing as also better mechanisms of energy absorption. The presented results in this work are of fundamental importance since they provide reliable controlling tools to determine the exact degree of crosslinking and workability, allowing product processing to the desired application.

\section{Acknowledgements}

The authors would like to thank Olin Corporation (Brazil) for kindly supplying the reactants.

The authors would like to acknowledge the financial support from the Coordenação de Aperfeiçoamento de Pessoal de Nível Superior (CAPES), from Conselho Nacional de Desenvolvimento Científico e Tecnológico (CNPq) and Fundação de Apoio à Pesquisa do Estado da Paraíba (FAPESQ) (Concession term: 017/2019). Professor Marcus Fook and Professor Renate Wellen (Number: 307488/2018-7) are CNPq fellows.

\section{References}

[1] Bucknall C. B., Gilbert A. H.: Toughening tetrafunctional epoxy resins using polyetherimide. Polymer, 30, 213-217 (1989). https://doi.org/10.1016/0032-3861(89)90107-9

[2] Hourston D. J., Lane J. M.: The toughening of epoxy resins with thermoplastics: 1 . Trifunctional epoxy resinpolyetherimide blends. Polymer, 33, 1379-1383 (1992). https://doi.org/10.1016/0032-3861(92)90110-I 
[3] Park S-J., Kim H-C.: Thermal stability and toughening of epoxy resin with polysulfone resin. Journal of Polymer Science Part B: Polymer Physics, 39, 121-128 (2000).

https://doi.org/10.1002/10990488(20010101)39:1<121::AID-POLB110>3.0.CO;2-N

[4] Kumar S., Krishnan S., Samal S. K., Mohanty S., Nayak S. K.: Toughening of petroleum based (DGEBA) epoxy resins with various renewable resources based flexible chains for high performance applications: A review. Industrial and Engineering Chemistry Research, 57, 2711-2726 (2018).

https://doi.org/10.1021/acs.iecr.7b04495

[5] Harani H., Fellahi S., Bakar M.: Toughening of epoxy resin using hydroxyl-terminated polyesters. Journal of Applied Polymer Science, 71, 29-38 (1999).

https://doi.org/10.1002/(SICI)10974628(19990103)71:1<29::AID-APP5>3.0.CO;2-7

[6] Hodgkin J. H., Simon G. P., Varley R. J.: Thermoplastic toughening of epoxy resins: A critical review. Polymers for Advanced Technologies, 9, 3-10 (1998).

https://doi.org/10.1002/(SICI)10991581(199801)9:1<3::AID-PAT727>3.0.CO;2-I

[7] Thomas R., Yumei D., Yuelong H., Le Y., Moldenaers P., Weimin Y., Czigány T., Thomas S.: Miscibility, morphology, thermal, and mechanical properties of a DGEBA based epoxy resin toughened with a liquid rubber. Polymer, 49, 278-294 (2008).

https://doi.org/10.1016/j.polymer.2007.11.030

[8] Tao L., Sun Z., Min W., Ou H., Qi L., Yu M.: Improving the toughness of thermosetting epoxy resins via blending triblock copolymers. RSC Advances, 10, 1603-1612 (2020). https://doi.org/10.1039/C9RA09183A

[9] Luo X., Ou R., Eberly D. E., Singhal A., Viratyaporn W., Mather P. T.: A thermoplastic/thermoset blend exhibiting thermal mending and reversible adhesion. ACS Applied Materials and Interfaces, 1, 612-620 (2009). https://doi.org/10.1021/am8001605

[10] Khor S. P., Varley R. J., Shen S. Z., Yuan Q.: Thermoreversible healing in a crosslinked polymer network containing covalent and thermo-reversible bonds. Journal of Applied Polymer Science, 128, 3743-3750 (2012). https://doi.org/10.1002/app.38578

[11] Balkenende D. W. R., Olson R. A., Balog S., Weder C., de Espinosa M. L.: Epoxy resin-inspired reconfigurable supramolecular networks. Macromolecules, 49, $7877-$ 7885 (2016).

https://doi.org/10.1021/acs.macromol.6b01491

[12] Lange R. F. M., van Gurp M., Meijer E. W.: Hydrogenbonded supramolecular polymer networks. Journal of Polymer Science Part A: Polymer Chemistry, 37, 36573670 (1999).

https://doi.org/10.1002/(SICI)1099-

0518(19991001)37:19<3657::AID-POLA1>3.0.CO;2-6
[13] Clark J. N., Daly J. H., Garton A.: Hydrogen bonding in epoxy resin/poly( $\varepsilon$-caprolactone) blends. Journal of Applied Polymer Science, 29, 3381-3390 (1984). https://doi.org/10.1002/app.1984.070291115

[14] Abbate M., Martuscelli E., Musto P., Ragosta G., Scarinzi G.: Toughening of a highly cross-linked epoxy resin by reactive blending with bisphenol A polycarbonate. I. FTIR spectroscopy. Journal of Polymer Science Part B: Polymer Physics, 32, 395-408 (1994). https://doi.org/10.1002/polb.1994.090320301

[15] Kulshreshtha B., Ghosh A. K., Misra A.: Crystallization kinetics and morphological behavior of reactively processed PBT/epoxy blends. Polymer, 44, 4723-4734 (2003).

https://doi.org/10.1016/S0032-3861(03)00347-1

[16] Francis B., Thomas S., Jose J., Ramaswamy R., Rao L. V.: Hydroxyl terminated poly(ether ether ketone) with pendent methyl group toughened epoxy resin: Miscibility, morphology and mechanical properties. Polymer, 46, 12372-12385 (2005).

https://doi.org/10.1016/j.polymer.2005.10.103

[17] Acebo C., Fernández-Francos X., Ferrando F., Serra À., Ramis X.: New epoxy thermosets modified with multiarm star poly(lactide) with poly(ethyleneimine) as core of different molecular weight. European Polymer Journal, 49, 2316-2326 (2013).

https://doi.org/10.1016/j.eurpolymj.2013.05.015

[18] Corre Y-M., Duchet J., Reignier J., Maazouz A.: Melt strengthening of poly(lactic acid) through reactive extrusion with epoxy-functionalized chains. Rheologica Acta, 50, 613-629 (2011).

https://doi.org/10.1007/s00397-011-0538-1

[19] Hameed N., Guo Q., Hanley T., Mai Y-W.: Hydrogen bonding interactions, crystallization, and surface hydrophobicity in nanostructured epoxy/block copolymer blends. Journal of Polymer Science Part B: Polymer Physics, 48, 790-800 (2010).

https://doi.org/10.1002/polb.21950

[20] Cholake S. T., Mada M. R., Raman R. S., Bai Y., Zhao X., Rizkalla S., Bandyopadhyay S.: Quantitative analysis of curing mechanisms of epoxy resin by mid- and near- fourier transform infra red spectroscopy. Defence Science Journal, 64, 314-321 (2014).

https://doi.org/10.14429/dsj.64.7326

[21] Finzel M. C., Delong J., Hawley M. C.: Effect of stoichiometry and diffusion on an epoxy/amine reaction mechanism. Journal of Polymer Science Part A: Polymer Chemistry, 33, 673-689 (1995).

https://doi.org/10.1002/pola.1995.080330409

[22] Xiong J., Liu Y., Yang X., Wang X.: Thermal and mechanical properties of polyurethane/montmorillonite nanocomposites based on a novel reactive modifier. Polymer Degradation and Stability, 86, 549-555 (2004). https://doi.org/10.1016/j.polymdegradstab.2004.07.001 
[23] Xing C., Matuana L. M.: Epoxidized soybean oil-plasticized poly(lactic acid) films performance as impacted by storage. Journal of Applied Polymer Science, 133, 43201/1-43201/8 (2016).

https://doi.org/10.1002/app.43201

[24] Cherdoud-Chihani A., Mouzali M., Abadie M. J. M.: Study of crosslinking AMS/DGEBA system by FTIR. Journal of Applied Polymer Science, 69, 1167-1178 (1998).

https://doi.org/10.1002/(SICI)10974628(19980808)69:6<1167::AID-APP14>3.0.CO;2-Q

[25] Cherdoud-Chihani A., Mouzali M., Abadie M. J. M.: Study of crosslinking acid copolymer/DGEBA systems by FTIR. Journal of Applied Polymer Science, 87, 2033-2051 (2003).

https://doi.org/10.1002/app.11389

[26] Al-Mulla E. A. J., Yunus W. M. Z. W., Ibrahim N. A. B., Rahman M. Z. A.: Properties of epoxidized palm oil plasticized polytlactic acid. Journal of Materials Science, 45, 1942-1946 (2010).

https://doi.org/10.1007/s10853-009-4185-1

[27] Xu Y-Q., Qu J-P.: Mechanical and rheological properties of epoxidized soybean oil plasticized poly(lactic acid). Journal of Applied Polymer Science, 112, 31853191 (2009).

https://doi.org/10.1002/app.29797

[28] Ni Y., Zheng S.: Influence of intramolecular specific interactions on phase behavior of epoxy resin and poly $(\varepsilon-$ caprolactone) blends cured with aromatic amines. Polymer, 46, 5828-5839 (2005).

https://doi.org/10.1016/j.polymer.2005.04.051

[29] Nguyen Q. T., Japon S., Luciani A., Leterrier Y., Månson J-A. E.: Molecular characterization and rheological properties of modified poly(ethylene terephthalate) obtained by reactive extrusion. Polymer Engineering and Science, 41, 1299-1309 (2001).

https://doi.org/10.1002/pen.10830

[30] Villalobos M., Awojulu A., Greeley T., Turco G., Deeter G.: Oligomeric chain extenders for economic reprocessing and recycling of condensation plastics. Energy, 31, 3227-3234 (2006).

https://doi.org/10.1016/j.energy.2006.03.026

[31] Xie Q., Liang S., Liu B., Fu K., Zhan Z., Lu L., Yang X., Lü F., Huang Z.: Structure, microparameters and properties of crosslinked DGEBA/MTHPA: A molecular dynamics simulation. AIP Advances, 8, 075332/1075332/14 (2018).

https://doi.org/10.1063/1.5041283

[32] Al-Itry R., Lamnawar K., Maazouz A.: Improvement of thermal stability, rheological and mechanical properties of PLA, PBAT and their blends by reactive extrusion with functionalized epoxy. Polymer Degradation and Stability, 97, 1898-1914 (2012).

https://doi.org/10.1016/j.polymdegradstab.2012.06.028
[33] Jaques N. G., de Lima Souza J. W., Popp M., Kolbe J., Fook M. V. L., Wellen R. M. R.: Kinetic investigation of eggshell powders as biobased epoxy catalyzer. Composites Part B: Engineering, 183, 107651/1-107651/37 (2020).

https://doi.org/10.1016/j.compositesb.2019.107651

[34] Gotro J., Prime R. B.: Thermosets. in 'Encyclopedia of polymer science and technology' (ed.: Mark H. F.), Wiley, San José, 1-75 (2002). https://doi.org/10.1002/0471440264.pst519.pub2

[35] Yin M., Zheng S.: Ternary thermosetting blends of epoxy resin, poly(ethylene oxide) and poly( $\varepsilon$-caprolactone). Macromolecular Chemistry and Physics, 206, 929-937 (2005). https://doi.org/10.1002/macp.200400512

[36] Zheng S., Guo Q., Chan C-M.: Epoxy resin/poly( $\varepsilon-$ caprolactone) blends cured with 2,2-bis[4-(4-aminophenoxy)phenyl]propane. II. Studies by Fourier transform infrared and carbon-13 cross-polarization/magicangle spinning nuclear magnetic resonance spectroscopy. Journal of Polymer Science Part B: Polymer Physics, 41, 1099-1111 (2003).

https://doi.org/10.1002/polb.10436

[37] Saeb M. R., Rastin H., Nonahal M., Paran S. M. R., Khonakdar H. A., Puglia D.: Cure kinetics of epoxy/ chicken eggshell biowaste composites: Isothermal calorimetric and chemorheological analyses. Progress in Organic Coatings, 114, 208-215 (2018).

https://doi.org/10.1016/j.porgcoat.2017.10.018

[38] Parameswaranpillai J., Sidhardhan S. K., Jose S., Hameed N., Salim N. V., Siengchin S., Pionteck J. R., Magueresse A., Grohens Y.: Miscibility, phase morphology, thermomechanical, viscoelastic and surface properties of poly( $\varepsilon$-caprolactone) modified epoxy systems: Effect of curing agents. Industrial and Engineering Chemistry Research, 55, 10055-10064 (2016).

https://doi.org/10.1021/acs.iecr.6b01713

[39] Schneider J., Shi X., Manjure S., Gravier D., Narayan R.: Epoxy functionalized poly(lactide) reactive modifier for blown film applications. Journal of Applied Polymer Science, 132, 42243/1-42243/7 (2015). https://doi.org/10.1002/app.42243

[40] Morell M., Erber M., Ramis X., Ferrando F., Voit B., Serra A.: New epoxy thermosets modified with hyperbranched poly(ester-amide) of different molecular weight. European Polymer Journal, 46, 1498-1509 (2010).

https://doi.org/10.1016/j.eurpolymj.2010.04.015

[41] Poel G. V., Goossens S., Goderis B., Groeninckx G.: Reaction induced phase separation in semicrystalline thermoplastic/epoxy resin blends. Polymer, 46, 1075810771 (2005). https://doi.org/10.1016/j.polymer.2005.09.013 
[42] Zhou J. L., Cheng C., Zhang H., Sun Z. Y., Zhu S., Yu M. H.: Dissolution behaviour of polyethersulfone in diglycidyl ether of bisphenol-A epoxy resins. IOP Conference Series: Materials Science and Engineering, IOP Publishing, 213, 012038/1-012038/8 (2017). https://doi.org/10.1088/1757-899X/213/1/012038

[43] Zhou T., Gu M., Jin Y., Wang J.: Effects of nano-sized carborundum particles and amino silane coupling agent on the cure reaction kinetics of DGEBA/EMI-2,4 system. Polymer, 46, 6216-6225 (2005).

https://doi.org/10.1016/j.polymer.2005.03.113

[44] Li L., Zeng Z., Zou H., Liang M.: Curing characteristics of an epoxy resin in the presence of functional graphite oxide with amine-rich surface. Thermochimica Acta, 614, 76-84 (2015).

https://doi.org/10.1016/j.tca.2015.06.006
[45] Nonahal M., Rastin H., Saeb M. R., Sari M. G., Moghadam M. H., Zarrintaj P., Ramezanzadeh B.: Epoxy/PAMAM dendrimer-modified graphene oxide nanocomposite coatings: Nonisothermal cure kinetics study. Progress in Organic Coatings, 114, 233-243 (2018).

https://doi.org/10.1016/j.porgcoat.2017.10.023

[46] Cai H., Li P., Sui G., Yu Y., Li G., Yang X., Ryu S.: Curing kinetics study of epoxy resin/flexible amine toughness systems by dynamic and isothermal DSC. Thermochimica Acta, 473, 101-105 (2008).

https://doi.org/10.1016/j.tca.2008.04.012 